\title{
Design and Tailoring of Alloys for Additive Manufacturing
}

\author{
T.M. POLLOCK, A.J. CLARKE, and S.S. BABU
}

\begin{abstract}
Additive manufacturing (AM) promises a major transformation for manufacturing of metallic components for aerospace, medical, nuclear, and energy applications. This perspective paper addresses some of the opportunities for alloy and feedstock design to achieve site-specific and enhanced properties not attainable by conventional manufacturing processes. This paper provides a brief overview of the role of powders, as well as solidification and solid-state phase transformation phenomena typically encountered during fusion-based AM. Three case studies are discussed that leverage the above to arrive at microstructure control. The first case study focuses on approaches to modify the solidification characteristics by in-situ alloying. The second case study focuses on the need for concurrent design of alloys and processing conditions to arrive at the columnar to equiaxed transition during solidification. The third case study focuses on the design of a cobalt alloy for AM, with emphasis on tailoring liquid and solid state phase transformations. The need for comprehensive knowledge of processing conditions during AM, in-situ and ex-situ probing of microstructure development under AM conditions, and post-print processing, characterization, and qualification are articulated for the design of future alloys and component geometries built by AM.
\end{abstract}

https://doi.org/10.1007/s11661-020-06009-3

(C) The Minerals, Metals \& Materials Society and ASM International 2020

\section{INTRODUCTION}

ADDITIVE manufacturing (AM) ${ }^{[1]}$ offers a broad suite of new opportunities for the design and production of metallic components, particularly for the aerospace, energy, and biomedical sectors, where component geometry is complex and production volumes are low to moderate. ${ }^{[2]}$ Furthermore, emerging print technologies offer the possibilities of on-demand manufacturing, customization, design complexities, part count reduction, reduction in lead time tooling and associated speedup in development, more efficient use of material, and energy and environmental benefits in terms of $\mathrm{CO}_{2}$ reduction. ${ }^{[3-8]}$ In recent years, there have been significant advances in the design and production of metallic $3 \mathrm{D}$ printing systems ${ }^{[2-6]}$ that use either wire or powder as input stock with conventional alloys. With these advances in machines, it is indeed possible to replace

T.M. POLLOCK is with the University of California Santa Barbara, Santa Barbara, CA 93106. A.J. CLARKE is with the Colorado School of Mines, Golden, CO 80401. Contact e-mail: amyclarke@mines.edu S.S. BABU is with the The University of Tennessee, Knoxville, TN 37996 and also with the Oak Ridge National Laboratory, Oak Ridge, TN 37831.

Manuscript submitted April 22, 2020.

Article published online October 16, 2020 existing manufacturing processes, such as casting, with AM for low-volume, high-value added and geometrically complex components. While there are many excellent studies that focus on the fundamentals of printing, heat treatment and mechanical properties of well-known printing alloys, ${ }^{[3-27]}$ the focus of this perspective is on emerging opportunities for tailoring the design of alloys for AM processes. This article is not intended to be a comprehensive review, but aims to highlight pathways for expanding the suite of available alloys for AM. The above literature clearly articulates that alloy design (i.e., definition of alloy chemistry and the associated specification ranges) for AM should be guided by application requirements (e.g., temperature and stress), size and complexity of printed component(s), service environment (e.g., wear, corrosive, static or dynamic loading), need for dual function (e.g., mechanical, neutron shielding ${ }^{[28]}$ and heat transfer properties ${ }^{[29]}$, complexity of the geometry, the type of AM processing machines and infrastructure, parameter scope, ability to accommodate post-processing, such as hot isostatic pressing (HIP) and/or heat treatment, ${ }^{[30]}$ and finally the business case. ${ }^{[31]}$ As with conventional materials processing approaches, it is essential to confirm that a given alloy can be fabricated with acceptable levels of defects, which inevitably arise along any material processing path and ultimately limit properties. 
The manufacturing of an aluminum gear box for RL-10 rocket engines provides an excellent example of the emerging challenges and opportunities for $\mathrm{AM} .^{[31]}$ The original cast component had external and internal geometrical complexity and was challenging to fabricate, due to its relatively large size $(\sim 300 \mathrm{~mm}$ in diameter). Due to the size of the component, AM was initially considered not to be relevant. However, with the introduction of new large format laser powder bed fusion (L-PBF) machines ${ }^{[32]}$ and the availability of highly weldable AlSil0Mg alloy powders, it was possible to print this gear box (Figure 1(a) and (b)). However, the default parameters used in the machine resulted in a significant volume fraction of distributed porosity (Figure 1(c)). At this juncture, there were two options: (a) search for a different alloy that did not show this tendency for pore formation or (b) modify the processing parameters to avoid the porosity. By tuning the processing parameters based on welding metallurgy principles, ${ }^{[3,34]}$ the porosity was reduced to acceptable levels (Figure 1(d)). This industrial-scale demonstration confirms the feasibility of using AM for niche applications in lieu of traditional manufacturing processes. Although for this alloy the defects were reduced to acceptable levels with process modifications, this is often not possible for an arbitrary combination of alloy and component. The results do lead to the question, however: What are the opportunities for alloy or material feedstock design, in addition to process parameter and
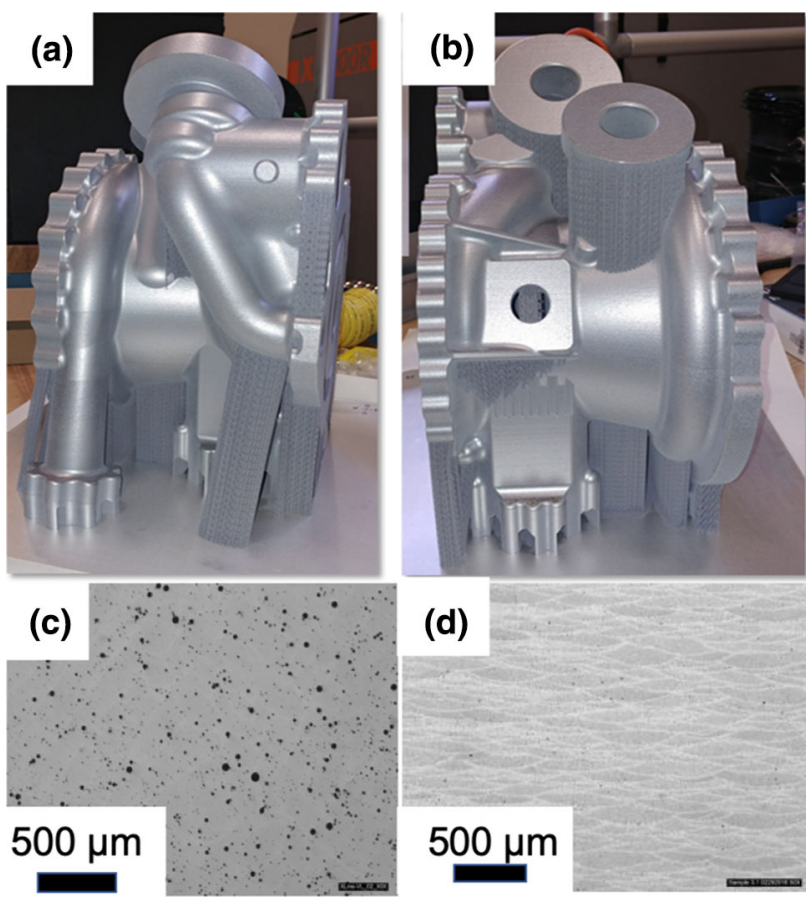

(d)

Fig. 1-Capability demonstration for L-PBF machines to make large-scale aluminum structures relevant to aerospace applications: (a) and (b) photographs of the gear box taken at two different angles, illustrating the geometrical complexity; (c) optical micrographs, showing the distribution of porosity with a non-optimized process in contrast with $(d)$ reduced porosity produced by optimized parameters. Photo courtesy: J. Haynes, AerojetRocketdyne, 2020. geometry optimization, to arrive at site-specific microstructures and enhanced properties not accessible by traditional manufacturing?

AM powder and wire feedstocks currently available are a result the tremendous progress made in the welding, ${ }^{[35]}$ thermal spray, ${ }^{[36]}$ and powder metallurgy industries over several decades. ${ }^{[37,38]}$ As a result, there are standards for powders ${ }^{[39]}$ and wire (welding consumables) ${ }^{[40,41]}$ for well-established $\mathrm{Fe}-$, $\mathrm{Ti}-, \mathrm{Al}-, \mathrm{Ni}-$, and Co-based alloys. Here we need to stress that the standards for existing wires and powders are not independent of the process. For example, solid welding wires used with inert gas shielding (e.g., Ar) do not have intentional additions of deoxidizers, while the welding wires used with mixed gases (e.g., $\mathrm{Ar}+\mathrm{CO}_{2}$ ) should have deoxidizers to react with dissolved oxygen in the melt pool. Wires typically range from $500 \mu \mathrm{m}$ to $1.5 \mathrm{~mm}$ diameter ${ }^{[42]}$ while powders are typically in the size range of 15 to $45 \mu \mathrm{m}$ and 45 to $106 \mu \mathrm{m}$ for laser- and electron beam-based powder bed fusion (PBF) processes, respectively. In this perspective paper, we limit our considerations to powder-based processes, where greater geometrical design complexity is possible relative to wire AM. Table I summarizes some of the conventional alloys that are currently available; it is noteworthy that the alloys highlighted in Table I do not constitute an exhaustive list, as powder manufacturing companies can easily expand the list to include emerging custom designed alloys.

Unfortunately, currently available powder alloys were not designed specifically for AM processes. Most of these alloys were designed for a given set of thermo-mechanical processing (TMP) histories typical to traditional manufacturing. Therefore, use of existing alloys may lead to sub-optimal, post-printed structures, when used with a wide range of processes and geometries. ${ }^{[42]}$ For example, the nickel-iron alloy IN 718 undergoes undesirable solid-state phase transformations during E-PBF, ${ }^{[4-45]}$ due to the fact that the powder bed temperature that produces crack-free material is coincident with the temperature where metallurgically undesirable phase transformations occur.

As understanding of the complex physics of the powder bed printing process evolves, ${ }^{[46-49]}$ opportunities exist for the design of alloys that are specifically tailored to the unique thermo-chemical and thermo-mechanical aspects of the printing process, and, importantly, are resistant to defect formation. ${ }^{[50,51]}$ In this paper, we address some of the design opportunities from the perspective of powders, solidification paths, and solidstate phase transformations, resulting in targeted microstructures and properties. Additionally, we offer some early alloy design case studies in the areas of superalloys and titanium alloys, and highlight some future challenges and opportunities.

\section{MATERIALS DESIGN OPPORTUNITIES FOR POWDER-BASED AM PROCESSES}

\section{A. Role of Powders}

Powders are a critically important element of the printing process, strongly influencing final component quality and defect content. For laser- and electron 


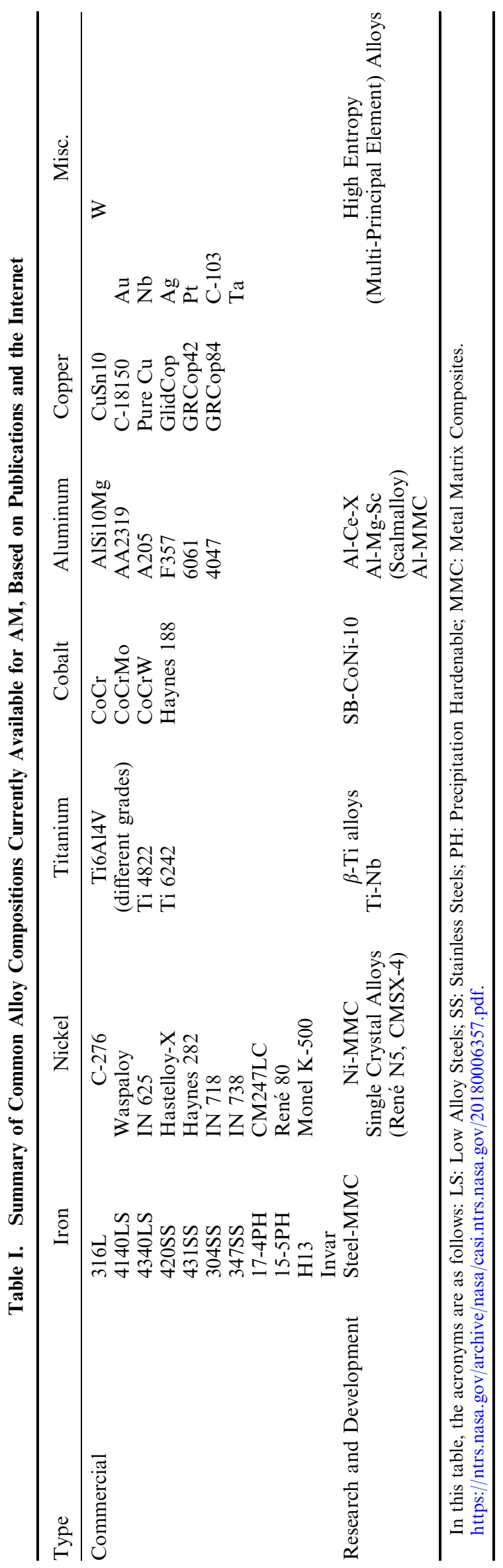

beam-based printing, spherical powders are desired for their favorable flow and uniform packing properties. For this reason, atomization is the major production route for powders, rather than reduction, electrolysis, or milling. There are a number of variants of atomization that produce spherical powders, ${ }^{[52-54]}$ including water, gas, plasma, plasma rotating electrode (PREP), and electrode inert gas atomization (EIGA). It is noteworthy that all powders may not be compatible with specific AM platforms. The cost of high-quality powders, especially with low levels of impurities such as sulfur, may comprise a significant fraction of the cost of 3D printing. ${ }^{[55]}$ This also poses a major barrier to the early stages of alloy design for AM, in that the conventional approach of synthesizing a suite of promising compositions for subsequent characterization and property measurements becomes cost prohibitive. This motivates an integrated computational materials engineering (ICME) approach ${ }^{[56-58]}$ for the design of alloy powders for AM.

Powders are nearly always fabricated from pre-alloyed feedstock (e.g., electrodes, ingots) in the atomization process. There have been efforts to by-pass alloy powder making by mixing elemental powders. However, this may not allow for complete mixing under all conditions, since elemental powders are often too coarse to mechanically mix and melt in a manner that ensures a homogeneous alloy in the liquid and subsequent LPB-printed states. ${ }^{[59]}$ It is noteworthy that in-process alloying is usually possible in laser directed energy deposition (DED) platforms by using different powder hoppers. ${ }^{[60]}$

Beyond the powder mixing approaches, at the earliest stage of the AM process, opportunities exist for the tailoring of powders ex-situ before processing (Figure 2) or in-situ during printing for the purpose of controlling printed grain structure. Columnar grains are prominent features of laser- and electron beam-based PBF 3D printing processes. The $3 \mathrm{D}$ electron backscatter diffraction (EBSD) TriBeam ${ }^{[61]}$ datasets shown in Figure 3 are roughly 5 build layers thick; many of the columnar grains, often near [001] orientation, continue through all 5 layers. As discussed in more detail in Section II-B, this arises due to the fact that high thermal gradients $(G)$ are generated in the melting process, promoting columnar growth along the crystallographically preferred [001] growth direction for cubic crystals. ${ }^{[2]}$ Columnar growth is further promoted by epitaxial growth of grains as the build process in the top layer partially re-melts material below the powder layer, propagating grains through many successive build layers. While columnar grains may be desirable for components that will operate at elevated temperatures, this grain morphology also promotes cracking, particularly in laser-based processes that typically have minimal preheating, resulting in anisotropic mechanical properties. ${ }^{[62-65]}$

A recent example (Figure 2) of ex-situ powder engineering to address the columnar grain issue is that of Martin et al. ${ }^{[66]}$ Standard powders for printing in a laser powder bed were modified by a functionalization process that attaches nanoparticles to the powder surface. Primarily focusing on grain refinement in pure 
aluminum and the $\mathrm{Al}$ alloy 7075, nanoparticles that could directly act as inoculants or indirectly serve as inoculants due to reactions during melting were introduced on standard laser size range powders. Nanoparticles of $\mathrm{Ta}, \mathrm{Nb}$, and $\mathrm{ZrH}$ (50 to $80 \mathrm{~nm}$ in size) all resulted in fine equiaxed grain structures with grain sizes less than $10 \mu \mathrm{m}$ (Figure 2), using standard Al print parameters in a Concept Laser M2 system. ${ }^{[6]}$ This approach enabled printing of a prominent aerospace alloy that was previously considered "unprintable" by refining grain size to a level that suppressed cracking during printing. Qiu and co-workers ${ }^{[6]}$ have also used $\mathrm{ZrN}$ inoculant powders blended with a $\beta$ titanium alloy Ti-13Mo (wt pct) to enhance grain nucleation. Interestingly, the addition of inoculants has previously been shown to refine the grain structure of welds. ${ }^{[68]}$ In both the $\mathrm{Al}$ and $\beta$-Ti systems, an important feature of the grain refinement process is the reaction that forms the nucleant particles above the peritectic temperature. This results in an obvious constraint with regard to the thermodynamics of the system and the associated level of loading of particles needed to induce nucleation. Inoculants conventionally blended with powder alloys or introduced into the pre-alloyed stock material for powder making have also demonstrated grain refinement in a number of other $\mathrm{Al}$ and Ti systems. ${ }^{[69-71]}$

The nano-functionalization approach has a number of advantages, including that a uniform distribution of the pre-inoculant material can be supplied, nanoparticles that do not melt during the printing process can be introduced, and new alloy compositions based upon readily available powders can be explored without the need for synthesis of specialized batches of powder. Reactive Additive Manufacturing (RAM) powder concepts, such as RAM Al alloys, are also being pursued to promote grain refinement during AM and the creation of metal matrix composites (MMCs) with desirable properties. ${ }^{[72]}$ Although promising results have been achieved with powder modification, as reported above, care must be taken with respect to deployment to industry, ${ }^{[73]}$ due to health and safety concerns ${ }^{[74]}$ and also reproducibility in the efficiency of grain refinement. The case study in Section II-E outlines an alternative approach, wherein in-situ powder engineering provides some of the benefits observed by ex-situ approaches, without the same potential health and safety concerns.

\section{B. Control of Solidification}

Since AM is comprised of many sequential melting events, achieving a microstructure that delivers requisite properties requires a detailed understanding of the solidification events associated with the print process and their dependence on alloy composition. Here a brief overview of solidification fundamentals is provided, with emphasis on foundational knowledge from welding and casting that can be leveraged for AM.

Irrespective of process, the solidification microstructure is controlled by the shape of the molten region and the operating conditions at the liquid/solid (L/S) interface, i.e., thermal gradients $(\mathrm{G}$ in the units of $\mathrm{K} / \mathrm{m})$ and liquid-solid interface velocity $(\mathrm{R}$, or $\mathrm{V}$, in the units of $\mathrm{m} /$

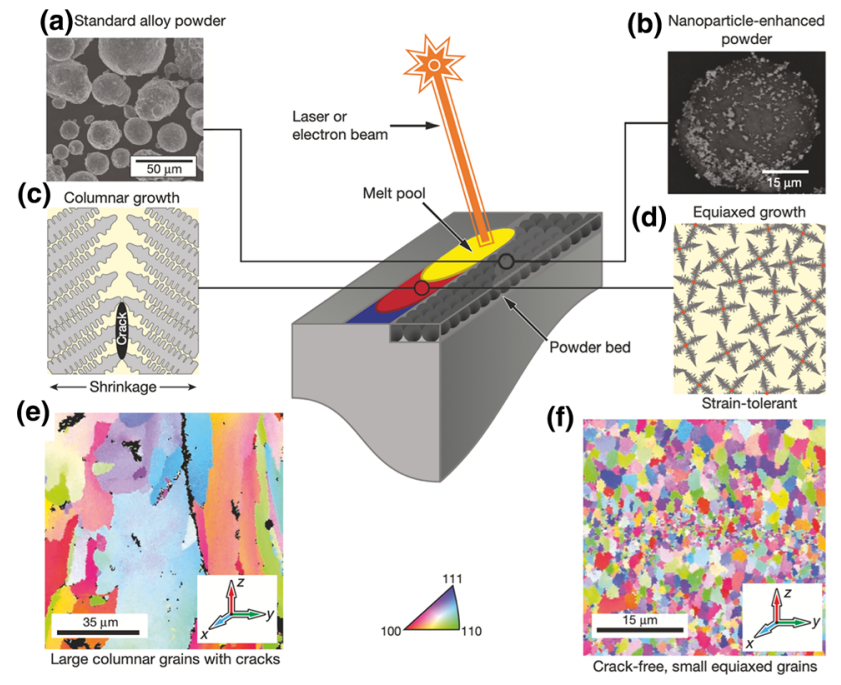

Fig. 2-Comparison of $(a),(c)$, and (e) as-processed aluminum alloy microstructure deposited with conventional and nanoparticle-enhanced powder $(b),(d)$, and $(f)$; The image was reproduced with permission from Ref. [66].

s). By manipulating these parameters, it is possible to control the microstructure evolution at site-specific locations. Foundational principles that control solidification structure during casting (large-scale melting) and welding (localized melting) ${ }^{[75-77]}$ can be leveraged to advance the development of AM (see Figure 4). For example, during fusion welding the melt pool size and shape reaches a steady state and thereby maintains $G$ and $\mathrm{R}$ consistently across the whole length of the weld. Therefore, one can expect consistent and reproducible microstructure for a given alloy system. This steady-state condition allows for fine tuning of process parameters to arrive at optimum welds without defects, delivering desirable microstructures and acceptable properties. Translating this solidification science approach to more complex AM processes is addressed in the case study in Section II-F.

An illustrative sample of the benefit of solidification science to welding (Figure 4. ${ }^{[78]}$ ) is apparent in keyhole electron beam welding of PWA1480 single crystals along the [100] direction. During keyhole welding, the liquid metal is vaporized, and the expanding gas pushes the liquid deeper, creating a funnel-like feature. It is important to note that keyhole formation in welding is well controlled, in contrast to L-PBF processes, where such processing-induced defects are often an outcome. During single crystal welding of PWA 1480, extensive cracking was observed only in a few locations oriented parallel and perpendicular to the welding direction (Figures 4(a) and (b)). The solidification cracks were associated with the boundaries between regions with predominantly single crystal structure and the regions containing large amounts of stray grains with random crystallographic orientations. To rationalize this microstructure evolution, the geometry of the melt pool shape was extracted (Figure 4(c)) by optical microscopy and analyzed with the geometrical model of Rappaz. ${ }^{[79,80]}$ Figure 4(c) illustrates the three-dimensional 


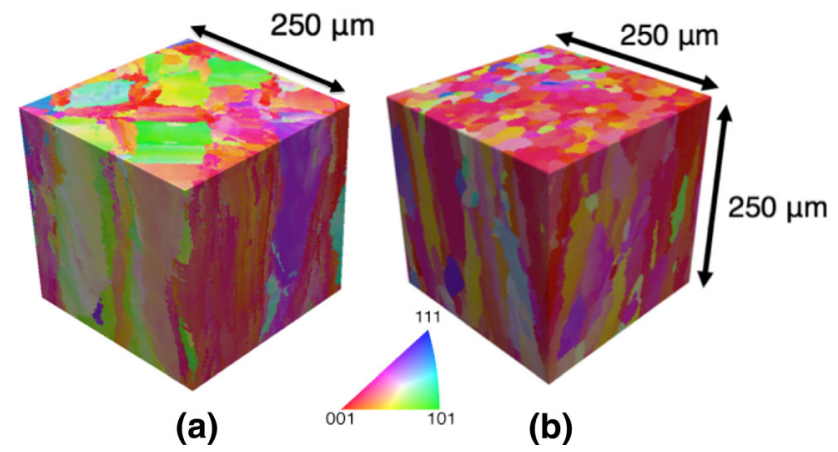

Fig. 3-3D EBSD TriBeam datasets of (a) SB-CoNi-10 printed by L-PBF and (b) IN 718 printed by E-PBF showing columnar grains that grow through multiple build layers. Build direction is vertical. Images courtesy of A. Polonsky and M. Echlin (UCSB).

shape of the weld pool with $\mathrm{X}, \mathrm{Y}$, and $\mathrm{Z}$ coordinates. The diagram also shows the contour projection of the weld pool shape in the XY plane. The dimensions are in $\mathrm{mm}$. The model uses two parameters: namely, $\theta$ the angle between normal vector $(\vec{n})$ to the liquid-solid interface and the vector representing the welding direction; and $\phi$ the angle between the $\vec{n}$ and the dendrite growth direction for a given $[h k l]$ primary dendrite growth direction. The velocity of the dendrite growing in $[h k l]$ direction is given by the following Eq. [1]

$$
\left|\vec{V}_{h k l}\right|=\left|\vec{V}_{\text {weld }}\right| \frac{\cos \theta}{\cos \phi} .
$$

The model can predict the normalized velocity of each dendrite growth direction with reference to welding velocity and melt pool shape dictated by $\theta$ and $\phi$. Typical plots for two weld pool geometries are shown in Figures 4(d) and (f). Experimental observations are shown in Figure 4(e). It is interesting to note that the [100] dendrite growth direction will be at the maximum velocity that is equivalent to that of electron beam welding speed, indicated by the contours of velocity ratio corresponding to 1.0. The geometry of the weld will force these regions to also have low thermal gradients. The welding and solidification theories also inform us that the tendency for constitutional supercooling, leading to equiaxed solidification, increases with an increase in the liquid-solid interface velocity and a reduction in temperature gradient. ${ }^{[81]}$

Therefore, as expected, stray grains were triggered when the $\left|\vec{V}_{100}\right|$ matches the welding velocity $(V)$. This condition is indicated by the shaded region with gray color that lies above the 1.0 velocity ratio $\left.\overrightarrow{(V}_{100} / V\right)$. In the above example, the melt pool remains in a symmetric keyhole mode, Figure 4b, and the welding direction aligns with [100] direction of the substrate.

This leads to two questions: (1) what will happen if the melt pool shape transitions to conduction mode from keyhole mode? (2) What will happen if the welding direction is at an angle to the substrate crystallographic basis?

The above questions are indeed addressed in Figures 4(f), (g), (h). With large crystallographic misorientation of the substrate with welding direction, the dendrite growth selection becomes asymmetric (see Figure 4(f)), i.e., the $\left|\vec{V}_{001}\right|$ becomes higher than that of welding velocity. This is indicated by the iso contour lines going above 1.0 in the yellow regions corresponding to [001] growth direction. The above published example shows, as long as one can describe the melt pool shape and the liquid-solid interface velocities and substrate crystallographic characteristics, the dendrite microstructure can be predicted. This concept is relevant to results presented in Section II-F. The above discussion leads to next question: can we leverage solidification theories to inform alloy development for control of microstructure in AM?

Aspects of solidification that can in principle be controlled by alloying to achieve location-specific properties in printed structure include (a) the columnar to equiaxed transition $(\mathrm{CET})^{[82]}$; (b) grain size and texture ${ }^{[83]}$; (c) phase selection during peritectic or eutectic solidification $^{[84,85]}$; (d) dendrite arm spacing ${ }^{[86]}$; (e) solute partitioning ${ }^{[87]}$; and (f) cracking tendency. ${ }^{[88]}$ Critical to this goal is information on thermal and mechanical boundary conditions operative during AM, which vary spatially and temporally. For example, the models for predicting cracking in welding and casting $^{[89-91]}$ have to be modified for cyclic variations in longitudinal and transverse stresses due to the layer by layer build process. ${ }^{[92]}$ In the model developed by Lee et al., ${ }^{[92]}$ the transients of compressive and tensile stress were predicted as a function of location and temperature for a given E-PBF layer. The results showed that cracking was asymmetric, because the tensile stresses developed only on one side of the build, while material was in the vulnerable temperature range.

\section{Tuning of Solid-State Transformations}

In many metals and alloys, the as-built solidification microstructure may be the final microstructure that controls the final properties of an AM component. The as-built microstructure may also limit the path for microstructure evolution in post-build thermal cycles. Ideally, the thermal cycles associated with the build cycle would optimize the microstructure; this could be accomplished through combined alloy and process design. For example, intrinsic heat treatment (IHT) during directed energy deposition (DED) recently resulted in the precipitation of $\mathrm{Al}_{3} \mathrm{Sc}$ in $\mathrm{Al}-\mathrm{Sc}-\mathrm{Zr}$ alloys during laser additive manufacturing in Reference 93.

Steels, Ti-, Al-, and Ni-base alloys that undergo solid-state transformations during AM may develop spatially dependent microstructures and properties. Kelly and Kempe ${ }^{[94,95]}$ indicated these microstructural heterogeneities during laser DED processing of Ti-6Al-4V (wt pct) alloys with the presence of layer bands, i.e., alternating layers of basketweave and colony $\alpha$-microstructure. The role of thermal gyrations within the phase transformation temperature range is elucidated with the work of Makiewicz et al. ${ }^{[96]}$ In this research, the laser DED process was used to deposit Ti-6Al-4V (wt pet) on top of a substrate. The builds 
were sectioned and analyzed in the as-built condition. The builds contained mostly columnar $\beta$-grains (Figure 5(a)) that form during solidification with traditional alpha $(\alpha)$ morphologies, including colony and basket weave structures. Hardness mapping across the build shows unusual gradation (Figure 5(b)) of the microstructure, moving from soft bottom to hard top regions. To rationalize this behavior, Makiewicz also performed detailed point counting of the microstructure using different key microstructural motifs, as shown in Figure 5(c). As expected, the hard regions correlated with the presence of predominantly basket weave structure compared to colony microstructure in the soft regions (Figures 5(d), (e), and (f)). This could be perplexing, since the builds were made under similar conditions in the top and bottom regions. However, detailed finite element analyses showed that there are subtle differences in thermal cycles from the top and bottom regions (Figures $5(\mathrm{~g})$ and $(\mathrm{h})$ ). For the bottom regions below a critical height, the peak temperatures associated with the thermal cycling do not go above the $\beta$-transus, while the regions above the critical height only cycle above the $\beta$-transus. As a result, the bottom regions undergo gradual changes in microstructure set up by the 1 st cycle within the $\alpha+\beta$ phase boundaries, leading to soft colony microstructure. In contrast, in the top regions the decomposition of $\beta$ phase only occurs at the last stage, leading to basket weave structure that is retained at room temperature. Interestingly, one can use these thermal cycles to bring about in-situ precipitation reactions during deposition of age-hardenable nickelbase alloys, such as alloy IN 718. ${ }^{[97]}$ The above examples illustrate that similar to solidification, the solid-state transformation is also affected by thermal signatures set up by the AM process.

Therefore, the details associated with thermal cycling (phase transformation temperatures and heating and cooling rates, for example) are important to solid-state microstructural evolution during AM. Figure 6 highlights aspects related to microstructure development in Ti-6Al-4V (wt pct) from solidification to the solid-state during powder bed fusion AM, including the precipitation of $\alpha$ and/or $\alpha^{\prime}$, the formation of which will be impacted by cooling rate. ${ }^{[98]}$ The addition of successive layers during laser direct metal deposition of Ti-6Al-4V (wt pct) has been reported to result in complex microstructural evolution in the solid-state. ${ }^{[99]}$ Single track layer deposition resulted in columnar prior $\beta$ grains and martensitic structure, which decomposed to a colony and basketweave microstructure with additional depositions, thereby influencing texture development. This work highlights the importance of local thermal conditions relative to critical phase transformation temperatures experienced during AM (e.g., the $\beta$ transus temperature in Figure 6), in addition to cooling rate, ${ }^{[100]}$ for example, impacting the formation of diffusional or diffusion-less products like martensite. ${ }^{[101]}$ Zhang et al. recently introduced the concept of Ti-Cu alloys for AM that may avoid the complexities of these transformations. Fine, equiaxed grains in the as-printed $\mathrm{Ti}-\mathrm{Cu}$
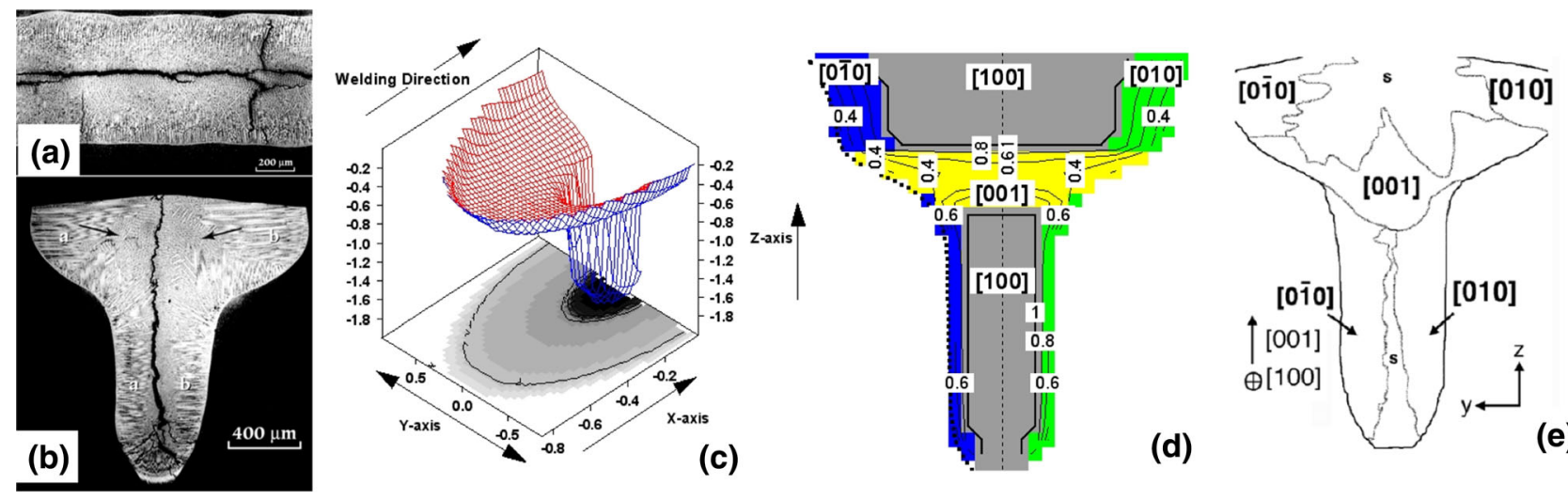

(e)
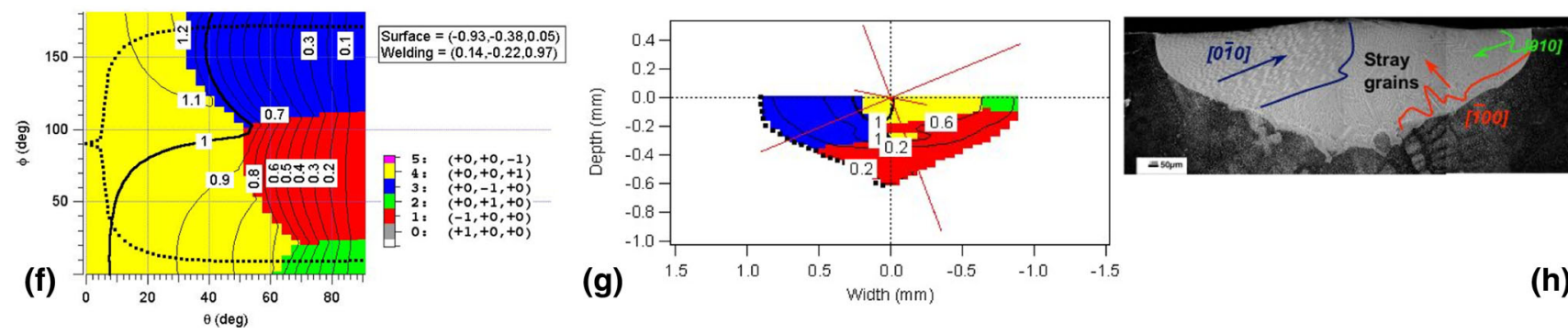

Fig. 4 - Optical micrographs of PWA1480 electron beam weld in the (a) $x-z$ and $(b) x-y$ sections, showing epitaxial growth and cracks along the $z$ and $y$ axis; $(c)$ 3D representation of the melt pool shape and $(d)$ predicted dendrite growth direction, which is compared with $(e)$ experimental observations. The contour lines in (d) and (e) connect the iso-velocity ratio $\left(V_{\mathrm{L} / \mathrm{S}} / V_{\text {weld }}\right)$ of the liquid/solid interface as a function of melt pool shape. Interestingly, the stray grains in the melt pool were restricted to the high-velocity regions. The geometry model was applied to a conduction model melt pool condition $(f),(g)$, and $(h)$, where the substrate crystal primary growth directions are highly misoriented with reference to the welding direction. The above modes are expected to be reproduced even in AM with changing substrate crystallographic orientations (Reproduced with permission from S.S. Babu.). 


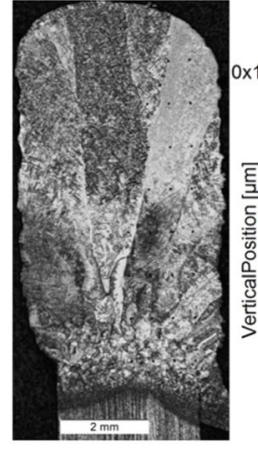

(a)

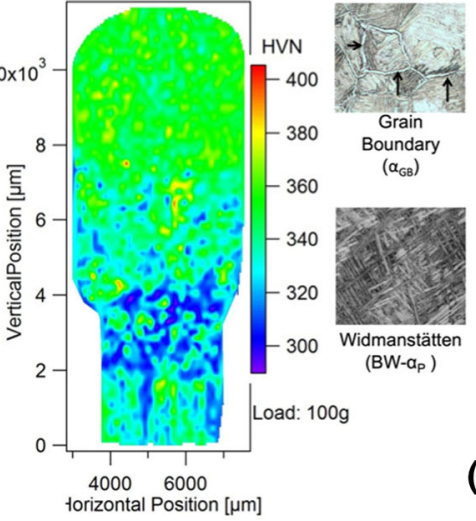

(b)

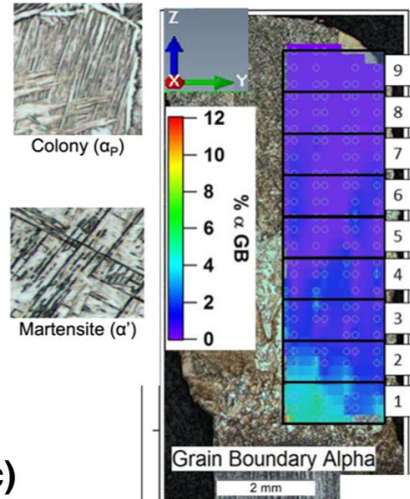

(d)

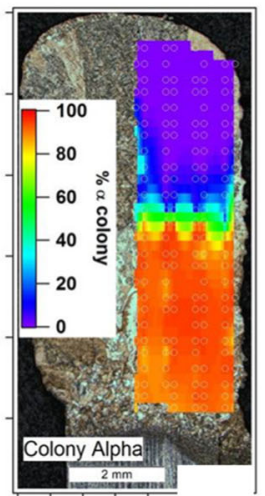

(e)

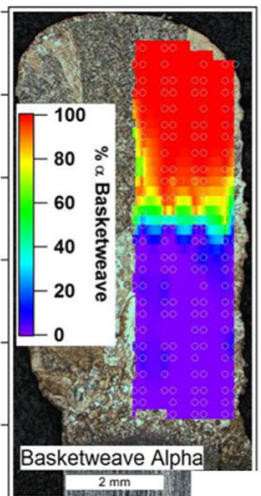

(f)

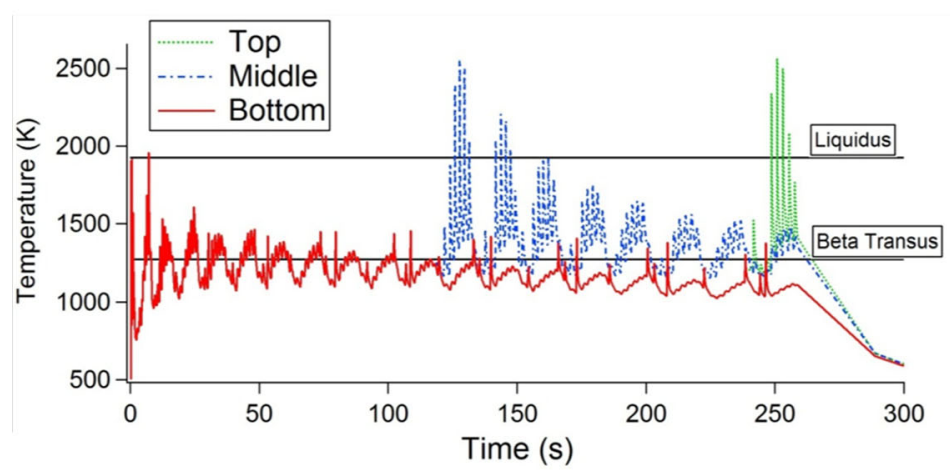

(g)

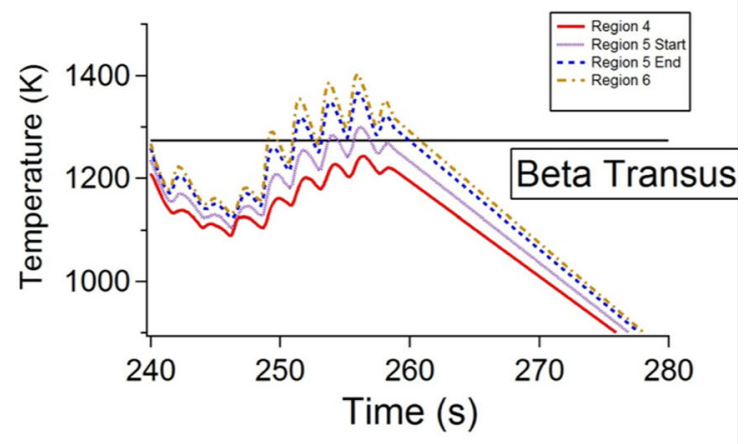

(h)

Fig. 5-Correlation of thermal signatures and microstructural heterogeneity in Ti6Al4V DED builds: (a) optical microstructure, showing columnar $\beta$-grain morphology; $(b)$ hardness map, showing mechanical heterogeneity; $(c)$ key microstructural features used to extract the microstructural heterogeneity shown in $(d),(e)$, and $(f)$. $(d)$ grain boundary alpha percentage; $(e)$ colony alpha percentage and $(f)$ basketweave alpha percentage; $(g)$ temperature $v s$ time of the top, middle, and bottom relative to the liquidus and beta transus temperatures; $(h)$ regions 5 and 6 show the transition in thermal signatures, in terms of the peak temperature just below and above the $\beta$-transus. (Reproduced with permission from S.S. Babu.).

alloys are thought to be achieved by constitutional supercooling ahead of the solid-liquid interface, promoting heterogeneous nucleation and inducing the CET. ${ }^{[02]}$

After solidification, solid-state phase transformation produces either a martensitic or a lamellar eutectoid product in $\mathrm{Ti}-\mathrm{Cu}$ alloys, depending upon the cooling rate experienced. Continued thermal cycling in the solid-state relative to the $\beta$ phase field ultimately results in a final eutectoid microstructure. Because the solidification microstructure in Ti-Cu alloys is replaced by solid-state phase transformation products, deconvoluting the relative contributions of liquid-solid and solid-solid phase transformations to the observed grain refinement remains challenging. ${ }^{[103]}$ It is also plausible that grain refinement occurs during solid-state thermal cycling in $\mathrm{Ti}-\mathrm{Cu}$ alloys. ${ }^{[103]}$ Such grain refinement by solid-state thermal cycling of a eutectoid product (e.g., pearlite) has previously been reported in steels, for example. ${ }^{[104]}$

Opportunities clearly exist to better match by alloy design the nucleation and growth of phases in the solid state to the thermal cycling conditions in AM, particularly in $\mathrm{Ti}$ alloys, ${ }^{[105,106]}$ in addition to solid-state microstructural aspects like metastable phase decomposition. ${ }^{[13,98,99]}$ For example, the role of thermal cycling in modifying the complex phase transformations in titanium aluminide intermetallic alloys during AM has recently been studied. Microstructural patterning of columnar and equiaxed grains containing lamellar microstructures and massive $\gamma$ phases have been reported ${ }^{[107]}$ Rapid solidification of a binary Ti-48Al (at. pct) has also been reported to result in a favorable fine-grained, dual phase $\alpha_{2}+\gamma$ microstructure under simulated AM conditions. ${ }^{[108]}$ In-situ high-energy X-ray diffraction has also been recently performed during a linear deposition of 308 stainless steel via wire arc additive manufacturing to observe liquid-solid and solid-solid phase transformations and to provide insights into the melt pool, thermal gradients, and the development of residual stresses. ${ }^{[109]}$ These examples highlight the need for improved understanding of transient thermal conditions and the unique thermal cycling encountered during AM on solid-state microstructural development.

\section{Case Studies in Alloy Design for AM}

The previous sections confirm that promising pathways for alloy design for AM include (1) tailoring of powder surfaces to achieve desired microstructure in the 
complex melt pool environment; or (2) the design of alloys that possess solidification characteristics and solid-state transformations that may be (in)sensitive to AM thermal signatures, thereby reducing the uncertainty brought about by geometrical variations and processing effects, and (3) the design of alloys with transformations and properties that match a specific $\mathrm{AM}$ approach (e.g., L-PBF or E-PBF). Most of the published work related to alloy design for AM falls into category (3), due to the need to satisfy the wide range of properties and engineering constraints discussed earlier. ${ }^{[110]}$ In the following sections, we present case studies for each of these areas, drawing on the research of the authors, to set the stage for future directions.

\section{E. Case Study 1: In-situ Tailoring of Powders via Liquid Gas Equilibrium}

\section{Concept}

Drawing from the welding metallurgy literature, it is well known that weld metal regions superheated to the boiling point often dissolve gases like $\mathrm{O}_{2}, \mathrm{~N}_{2}, \mathrm{CO}$, and $\mathrm{CO}_{2}$. This leads to the obvious question: is it possible to introduce these gases to react with other elements in the powder to form strengthening particles such as oxides, carbides, and nitrides during AM? This phenomenon is often seen in self-shielded flux cored arc welds that are welded in air, without any shielding. In order to fix the dissolved oxygen and nitrogen, steel consumables are alloyed up to a maximum of $1 \mathrm{wt}$ pct, with other deoxidizers such as titanium. ${ }^{[111]}$ The added aluminum and titanium then react with dissolved oxygen and nitrogen to form $\mathrm{AlN}$ and $\mathrm{Al}_{2} \mathrm{O}_{3}$, as well as $\mathrm{Ti}(\mathrm{CN})$, respectively.

\section{Approach}

This concept has been proven through a laser surface alloying experiment. ${ }^{[112]}$ In order to make a hard coating on a 1020 mild steel substrate, 431 steel powder was mixed with $\mathrm{TiC}$ powders in an 80:20 mixture. The powder size range of commercially pure steel powder varied from 44 to $177 \mu \mathrm{m}$. The TiC carbide sizes varied from 44 to $100 \mu \mathrm{m}$. These powders were processed with a Nd-YAG laser with a laser power of $2430 \mathrm{~W}$ and 100 pct Argon and 100 pct Nitrogen shielding after pre-placing on a 1020 mild steel substrate. The results are summarized in Figure 7.

\section{Results}

The processed regions shown in Figures 7(a) and (b) do not show large differences in the bead morphology or etching contrast associated with the HAZ (i.e., darkly etching regions), suggesting that thermal gradients in the HAZ are more or less similar. However, optical microscopy of the nitrogen shielded laser deposit showed copious formation of $\operatorname{Ti}(\mathrm{CN})$, while argon shielded regions did not show this behavior. The EBSD confirmed that there is no special correlation between rosette-type $\mathrm{Ti}(\mathrm{CN})$ that formed from the liquid. In addition, the EBSD confirmed the formation of fine BCC grains around these carbides. Furthermore, a fine distribution of $\operatorname{Ti}(\mathrm{CN})$ was also seen in the
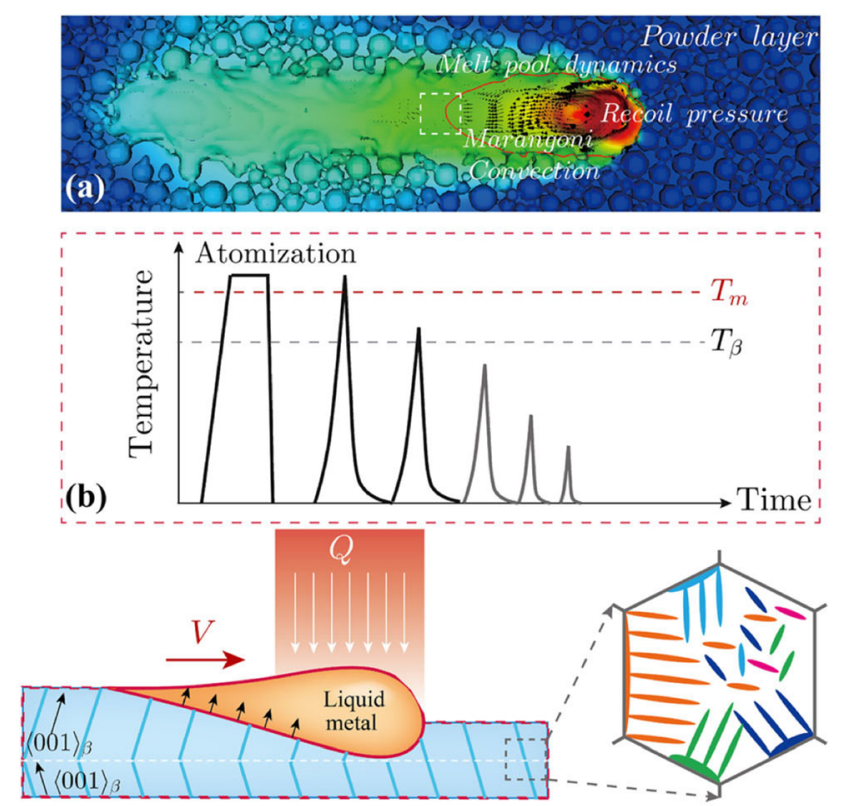

(c)

(d)

Fig. 6-(a) The dominant physical phenomena (such as heat transfer, molten pool fluid flow, and phase transitions); (b) thermal cycles at a monitoring location highlighted by a dashed square in (a); (c) the attending solidification of $\beta$ phase and $(d)$ precipitation of $\alpha$ and/or $\alpha^{\prime}$ from $\beta$ matrix during powder bed fusion AM. Reprinted from R. Shi, S. Khairallah, T. Wook Heo, M. Rolchigo, J.T. McKeown, M.J. Matthews, JOM, 2019, 71:3640-3655. (Reproduced with permission.).

inter-dendritic boundaries. Interestingly, the nitrogen addition increased the hardness from 574HV to $724 \mathrm{HV}$. The increased hardness is associated with these primary $\mathrm{Ti}(\mathrm{CN})$, as well as fine ferrite that is seen. The above conclusions are made based on detailed discussions provided in Reference 112, which show the distribution of hardness in the fusion zone and heat-affected zone, as well as detailed thermodynamic calculations showing the role of added nitrogen to the weld metal region.

The above results confirmed that laser processing with in-situ alloying can be used as a tool to produce oxide-, carbide-, or nitride-based MMCs with complex geometry. Recently, this approach has been extended to L-PBF conditions ${ }^{[113]}$ with the addition of $\mathrm{CO}_{2}$. Preliminary results show this leads to the presence of fine distribution of oxides and some improvement in compressive high-temperature properties. With proper care, in-situ gas-based alloying may also provide an alternative pathway to obtain site-specific properties, based on particulate strengthening.

\section{Limitations}

Although gas-based, in-situ alloying appears to be easier than other powder-based alloying, care must be taken during laser processing for safety reasons. One could be tempted to process under much more reactive gases such as methane. Although welding has been demonstrated under oil ${ }^{[114]}$ safely, the key requirement is that there is no oxidizing atmosphere. Therefore, the 
authors recommend caution while processing under reactive gases.

\section{F. Case Study 2: Alloy Design for Control of Solidification}

\section{Concept}

As highlighted in Section II-B, the solidification science that underpins the extensive development of casting and welding processes can be transferred to the challenge of designing alloys for AM. This requires extensive knowledge of the alloy-sensitive processes that occur at the solid-liquid interface during melting and solidification. Therefore, one can envision that by coupling solidification interface response function theories with multicomponent Calphad-type thermodynamic calculations, one could design AM alloys that can arrive at targeted solidification microstructure, as well as targeted solid-state transformations.

\section{Approach}

This concept was evaluated to design Ni-base superalloys that can be printed with predominantly directional (columnar) grain growth with minimal tendency for stray grains and targeted fractions of $\gamma^{\prime}$ phase within an AM build. Alloy design calculations were performed by writing an advanced programing interface (API) with ThermoCalc $\mathbb{R}$ software, which is one of the most highly developed ICME tools. ${ }^{[64]}$ The target requirements were set as following: (a) $200{ }^{\circ} \mathrm{C}$ temperature difference between the solidus and liquidus temperatures; (b)
CET boundaries below that of IN 718 and (c) $\gamma^{\prime}$ phase percentage of 70 pct at $750{ }^{\circ} \mathrm{C}$. The first condition was based on extensive welding metallurgy results and previous welding metallurgy research ${ }^{[89,90]}$ that showed minimal weld cracking and reduced stray grains with alloys that have a solidification temperature interval of $200{ }^{\circ} \mathrm{C}$. The second condition was chosen to promote a columnar grain structure, and the third to arrive at a $\gamma^{\prime}$ phase percentage that is similar to other commercial alloys that will lead to good high-temperature strength. By coupling the solidification interface response function calculations for the CET with estimated $\gamma^{\prime}$ phase fraction, ${ }^{[115]}$ two candidate nickel alloy compositions were designed, Figure 8(a). The solute effects on solidification resulted in CET boundaries that were lower in G-R space, compared to the baeline alloy 718, Figure 8(b). The powders made with these compositions were processed by Frederick ${ }^{[16]}$ using the E-PBF process.

\section{Results}

Final optimization calculations using the above constraints were performed and two alloys were designed: (a) Ni6666: Ni-6Cr-6Al-6Ta (wt pct) and (b) Ni106: Ni-10Cr-6Al (wt pct). Small batches of these powders were created for these alloy compositions by Oerlikon. EBSD of the solidification grain structure was evaluated, as shown in Figure 8(c). Although not surprising, the E-PBF process always leads to directional growth across the build, with some misorientations near the edge of the build (denoted as left in the images). The
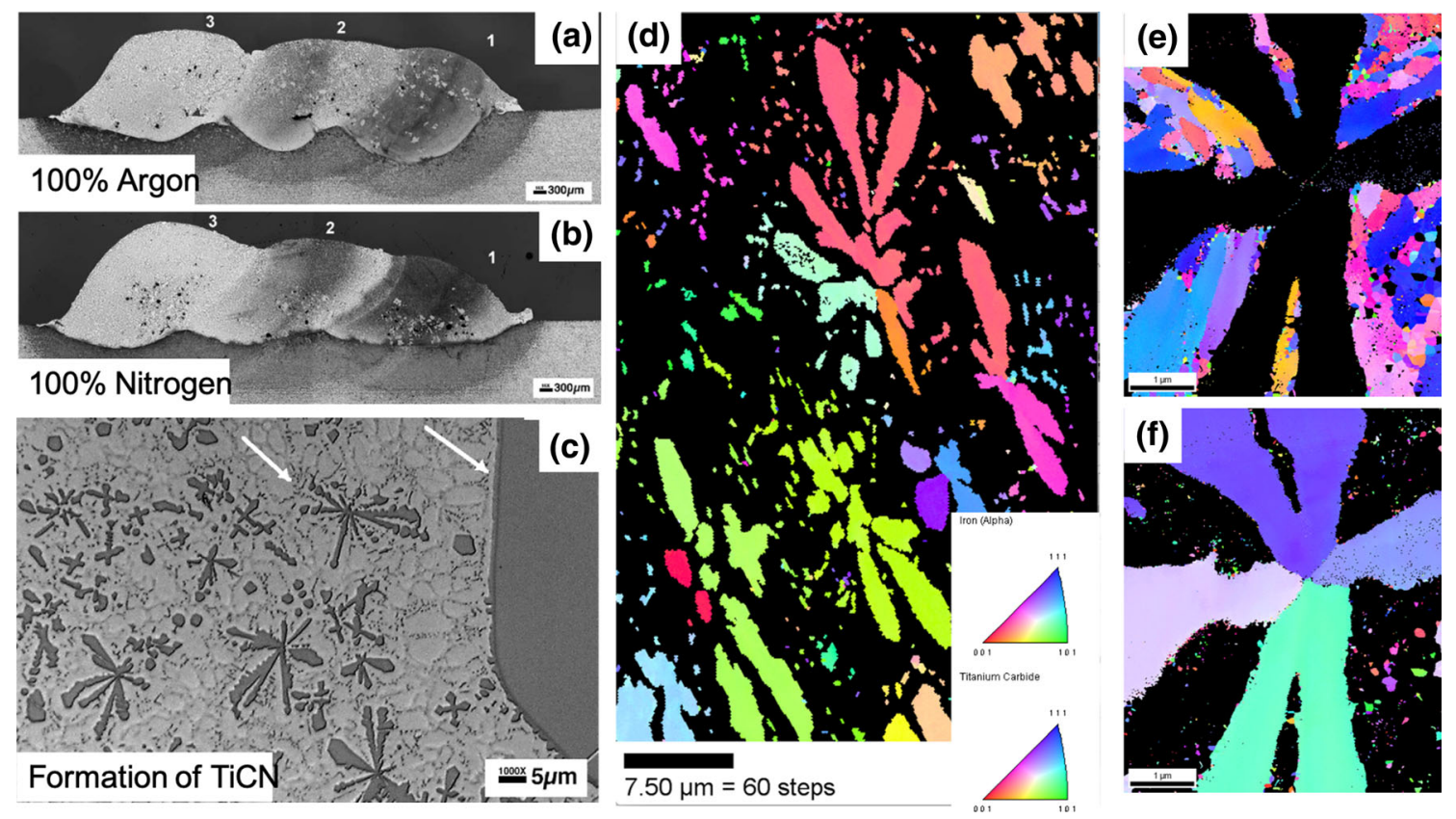

Fig. 7-Summary of results related to in-situ alloying through gas: (a) deposit made with 100 pct Argon shielding; $(b)$ deposit with 100 pct $\mathrm{N}_{2}$ shielding; (c) the optical micrographs confirmed the in-situ formation of $\mathrm{Ti}(\mathrm{CN})$. The white arrow at the left point to the $\mathrm{Ti}(\mathrm{CN})$ that formed under in-situ conditions and the right white arrow point to the large original TiC that was pre-placed. (d) EBSD image (obtained from XZ sections, selective imaging of $\mathrm{TiC}$ ) from the lastly deposited melt pool confirm the rosette-type morphology typically seen in $\mathrm{Ti}(\mathrm{CN})$ that forms from liquid steel; the color codes correspond to the inverse pole figure for TiC shown here; it is interesting to see many arms of the dendrite rosette share the same orientation. Selective EBSD imaging of $(e) \mathrm{BCC}$ and $(f) \mathrm{Ti}(\mathrm{CN})$ from a different location confirm the formation of sub- $\mu \mathrm{m}$ ferrite grains around large $\operatorname{Ti}(\mathrm{CN})$ particles. Reproduced from Ref. [112] with permission. 
as-built microstructure of both alloys showed the presence of $\gamma^{\prime}$ phase fraction across the build, although there is a systematic variation in $\gamma^{\prime}$ size brought about by the differences in time spent during processing. The results do support the notion of alloy design based on the interface response function theories published elsewhere $^{[15]}$ and estimated phase fractions predicted by ThermoCalc ${ }^{\circledR}$ simulations.

The above experiment shows that for well-established processing conditions and a given geometry, one may be able to arrive at a Ni-base superalloy composition that will lead to targeted grain structure and solid-state decomposition. This allows for the creation of a final component by E-PBF process, without the need for post-process heat treatments. In addition, due to slow cooling from build temperature in E-PBF, the solid-state decomposition of $\gamma$ phase is indeed complete in the as-built condition.

\section{Limitations}

Although one can claim success in coupling solidification interface response function theories with alloy design calculations using Thermo-Calc $\AA$, it is important to note that this result is specific to the build geometry and the E-PBF processing conditions used in this experiment. Frederick et al. ${ }^{[117]}$ argue that subtle variations of geometry with reference to processing conditions (i.e., reduction of $\mathrm{G}$ and increase in $\mathrm{R}$ ) close to the boundaries may usher in equiaxed grain growth. In addition, Frederick also notes that due to high volume fraction of $\gamma^{\prime}$ phase, in certain locations small cracks were observed due to local changes in thermal gradient, which may in turn lead to tensile stresses. The linkage between geometry and scan strategies dictating the spatial variations of $\mathrm{G}$ and $\mathrm{R}$ must be considered to understand the uncertainty in microstructure evolution during AM. Future work is also necessary to understand the role of elemental partitioning characteristics and its effect on high-temperature creep properties. Additionally, a broader suite of tools, as discussed in the case study outlined in Section II-G, are needed to consider the broader suite of properties typically required for engineering components.

\section{G. Case Studies: Alloy Design and Tailoring of High-Temperature Transformations}

\section{Concept}

An emerging class of Co-base alloys strengthened with $\mathrm{Co}_{3}(\mathrm{Al}, \mathrm{W}) \mathrm{Ll}_{2}$ intermetallic precipitates offers

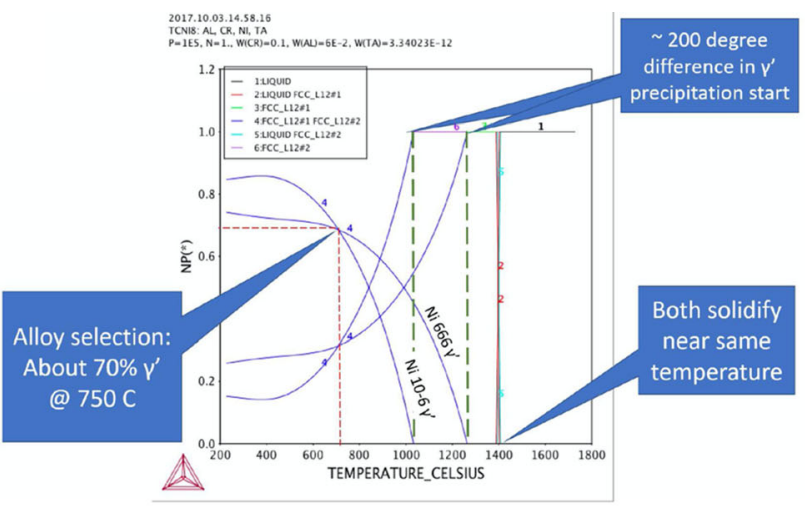

(a)

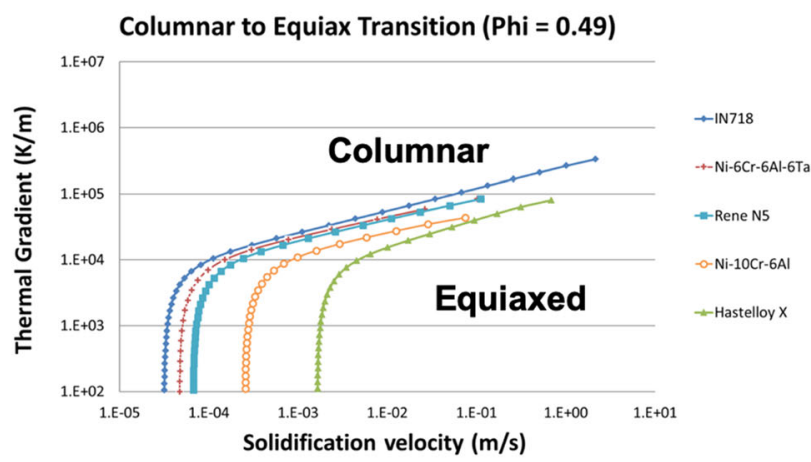

(b)

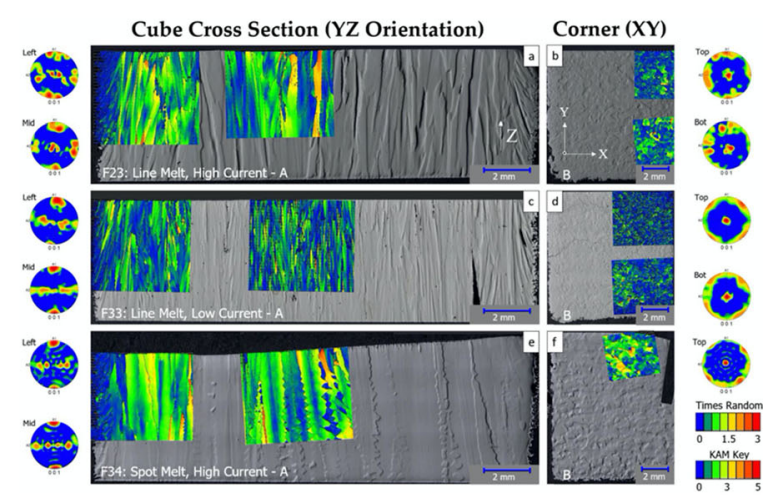

(c)

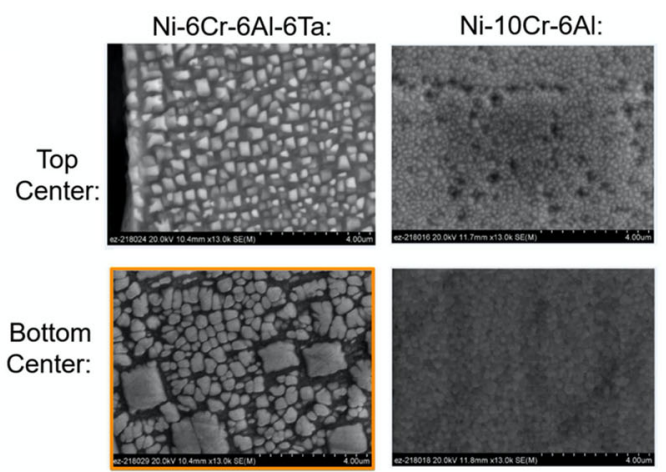

(d)

Fig. 8-(a) Calculated phase fraction variations for newly designed Ni6666 and Ni106 alloys and the design rules for arriving at targeted solidification and solid-state decomposition characteristics; $(b)$ the location of the CET lines for the current alloys are compared with commercial alloys; (c) EBSD from selected locations within Ni6666 samples, showing the presence of predominantly columnar grains in XZ section and also fiber texture in the XY section; the pole figures are extracted from detailed EBSD images from the left and middle section of the builds. $(d)$ scanning electron micrographs of the $\gamma^{\prime}$ phase and its morphology at different locations, showing more than 70 pct $\gamma^{\prime}$ phase. (Courtesy: Curtis Frederick, reproduced from $\mathrm{PhD}$ thesis with permission.). 
some potentially attractive properties for high-temperature aerospace components compared to $\mathrm{Ni}$-base alloys or conventional solid solution-strengthened Co-base alloys. ${ }^{[118-121]}$ Early variants of these systems have been studied with conventional wrought processing or Bridgman single crystal growth as the processing path. ${ }^{[122-127]}$ The emergence of this new class of alloys was coincident with the thrust to develop new ICME tools, creating the opportunity for the design of alloys matched to PBF additive processes. ${ }^{[128,129]}$ In this case study, the primary goals for alloy design were good high-temperature strength up to $1000{ }^{\circ} \mathrm{C}$ (achieved by precipitation of a high volume fraction of the $\mathrm{Ll}_{2}$ phase), $\mathrm{Ll}_{2}$ solvus between $1100{ }^{\circ} \mathrm{C}$ to $1250{ }^{\circ} \mathrm{C}$, high solidus and liquidus temperatures, high resistance to oxidation via alumina formation, and favorable printability. Nickel-base alloys strengthened with high volume fractions of $\mathrm{L}_{2}$ are well known for their tendency to crack during PBF printing. ${ }^{[64]}$ In these alloys, the $\mathrm{Ni}_{3} \mathrm{Al}$ phase exists to just a few degrees below the solidus temperature, and thus it was hypothesized that a gap of $>50{ }^{\circ} \mathrm{C}$ between the solidus and solvus temperatures would increase cracking resistance, while still maintaining a high volume fraction of precipitates at elevated temperatures.

\section{Approach}

A suite of computational and high-throughput experimental tools were developed/integrated to explore the large multicomponent compositional space. The design tools include density functional theory (VASP), cluster-assisted statistical mechanics (CASM), phase field dislocation dynamics, Calphad calculations, ion-plasma deposition combinatorial libraries, and high-throughput analyses of oxide formation during high-temperature exposure. ${ }^{[130-136]}$ Use of these tools enabled the large potential design space to be explored efficiently and in a non-linear manner, based upon design goals.

Electronic structure calculations using density functional theory (DFT) were performed to investigate the thermodynamic stability of the potential crystal structures in the Co-Al-W ternary and higher order systems, as well as to calculate superlattice intrinsic fault (SISF) energies to maximize strength. Calculations indicated that $\mathrm{Ti}$, $\mathrm{Ta}$, and $\mathrm{Nb}$ were favorable alloying additions. $^{[128]}$ The full generalized stacking fault (GSF) surface was also calculated to study dislocation mechanisms in more detail by phase field dislocation calculations to further adjust composition. ${ }^{[136]}$ A Calphad database was also developed ${ }^{[135]}$ and subsequently incorporated into the CompuTherm PanCobalt database. Thermodynamic calculations were used to tune the Ni content to increase the $\mathrm{L}_{2}$ solvus temperature to the desired range, and to predict phases present across composition space in the combinatorial studies.

Alloy design considered the complexity of cracking mechanisms that can occur in the late stages of solidification and shortly thereafter in the solid state, as studied in detail in the welding literature. ${ }^{[94,137]}$ Mild segregation during solidification, i.e., distribution coefficients, $k$, near 1.0 , along with relatively narrow freezing ranges was targeted. ${ }^{[120,124]}$
In high-temperature oxidizing environments, ternary Co-Al-W alloys have limited oxidation resistance, forming non-protective $\mathrm{CoO}$ and mixed spinels. ${ }^{[120,138]}$ Because first principles modeling of non-stoichiometric oxides is extremely challenging, a combinatorial library approach was developed. The combinatorial approach ${ }^{[133,139]}$ was coupled with rapid screening based on Photo-Stimulated Luminescence Spectroscopy (PSLS $^{[140]}$ and the Calphad database ${ }^{[135]}$ to outline regions of composition space giving rise to $\alpha-\mathrm{Al}_{2} \mathrm{O}_{3}$ scales. Ion-plasma deposition used five cathodes of different compositions to create three libraries covering a spectrum of Co-Ni-Al-W-Cr-Ta alloy compositions with 234 samples. ${ }^{[139]}$

\section{Results}

Combining these ICME tools and starting from the composition of an alumina forming IPD alloy of composition Co-32.4Ni-11.7Ni-4.4W-3.3Cr-1.5Ta (at. pct), three additional alloys with small variations in composition were arc melted. ${ }^{[128]}$ After analysis of microstructure and phases present, a final composition possessing a desirable two-phase microstructure was selected for (a) single crystal growth to measure basic properties and (b) 3D printing to assess its behavior in both laser- and electron beam-based PBF build approaches. The alloy, designated SB-CoNi-10, has a nominal composition of Co-36.5Ni-13.2Al-6.0Cr-3.5Ta-1.0W (at pct) and density of $8.65 \mathrm{~g} / \mathrm{cm}^{3}$. The $\mathrm{L}_{2}$ solvus temperature of this alloy is $1204^{\circ} \mathrm{C}$, while the solidus and liquidus were at $1329{ }^{\circ} \mathrm{C}$ and $1381{ }^{\circ} \mathrm{C}$, respectively, giving a solid to liquid gap of $52{ }^{\circ} \mathrm{C}$ and a single-phase solid solution window of $125^{\circ} \mathrm{C}$. Printing was conducted in a SLM Solutions 125 L-PBF System (Carpenter Technology) and an Arcam Q10+ E-PBF (Oak Ridge National Laboratory). Printed samples were tensile tested at a rate of $10^{-4} / \mathrm{s}$ in the as-printed and in the hot isostatically pressed (HIP) + heat-treated condition, with a $1245^{\circ} \mathrm{C} / 100 \mathrm{MPa} / 4$-hour $\mathrm{HIP}+$ $1245^{\circ} \mathrm{C} / 2$-hour solution and $1000{ }^{\circ} \mathrm{C} / 50$-hour age to produce the microstructure shown in Figure 10(c). Additional details are given elsewhere. ${ }^{[129]}$

Figure 9 shows a cross section normal to the [001] single crystal growth direction of the SB-CoNi-10 alloy and the associated analysis of distribution coefficients extracted from electron microprobe scans of the dendritic structure; details of this analysis are given elsewhere. ${ }^{[128,129]}$ Significantly, the degree of segregation of the alloying elements as a function of fraction solid is less severe compared to nickel-base alloys, which also have wider freezing ranges compared to the CoNi alloys. ${ }^{[141]}$ The combined effect of lower solidification segregation, lower freezing ranges, and the $125^{\circ} \mathrm{C}$ solidus to solvus gap likely suppresses the tendency for liquid-mediated cracking during printing and subsequent cooling below the solidus temperature. Evidence for this favorable "printability" is a single electron beam track melting event where no cracking occurs along the high-angle boundary, Figure 10(a), the high ductility of the as-printed samples (elongation $=33$ pct), Figure $10(d)$, and the ability to print blade-shaped samples without cracking in E-PBF and L-PBF, 
Figures 10(e) and (f), respectively. It is interesting to see the mode of solidification in Figure 10(a), similar to the crystallographic discussions presented earlier in Figure 4. Unfortunately, the thermodynamic database does not accurately predict Scheil solidification curves for these alloys, hindering modeling and demonstrating the need for further development of thermodynamic databases in this compositional domain. Nevertheless, the design tools have been able to identify a promising composition from the "printable" point of view, with

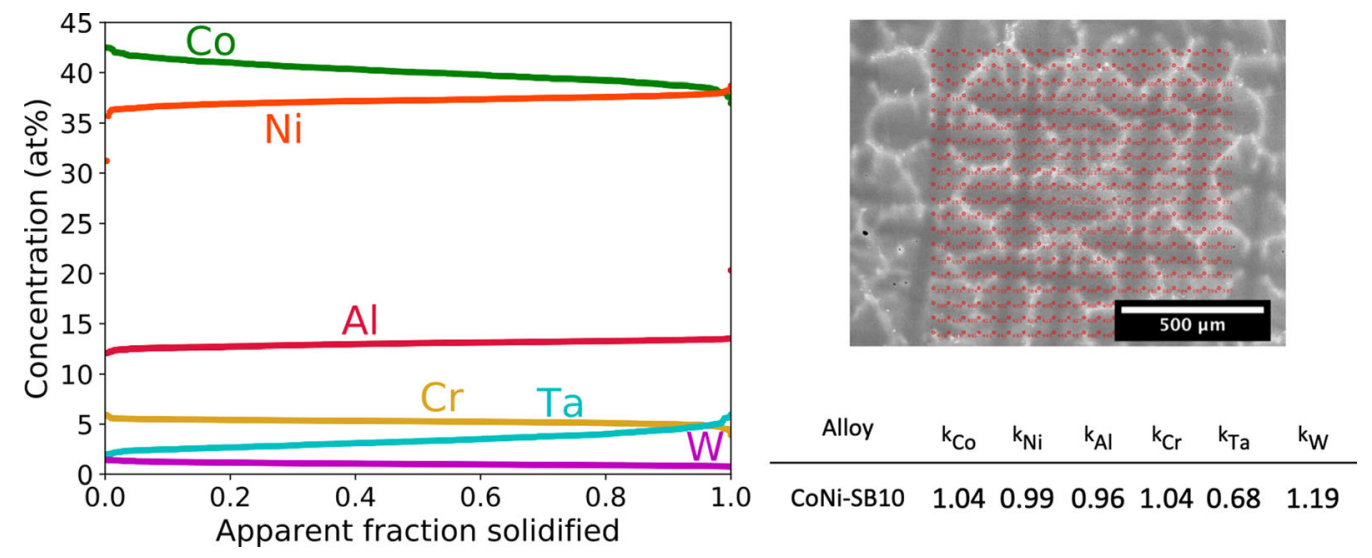

Fig. 9-(Left) Results of sorted $20 \times 20$ microprobe grid scans (locations indicated by red markers) across a $1 \mathrm{~mm}^{2}$ region of a single crystal sample sectioned normal to the [001] growth direction and (right) associated distribution (partition) coefficients extracted from a Scheil equation fits the data. Note the mild segregation with distribution coefficients of the alloying elements near 1.0. Images courtesy of S.P. Murray.

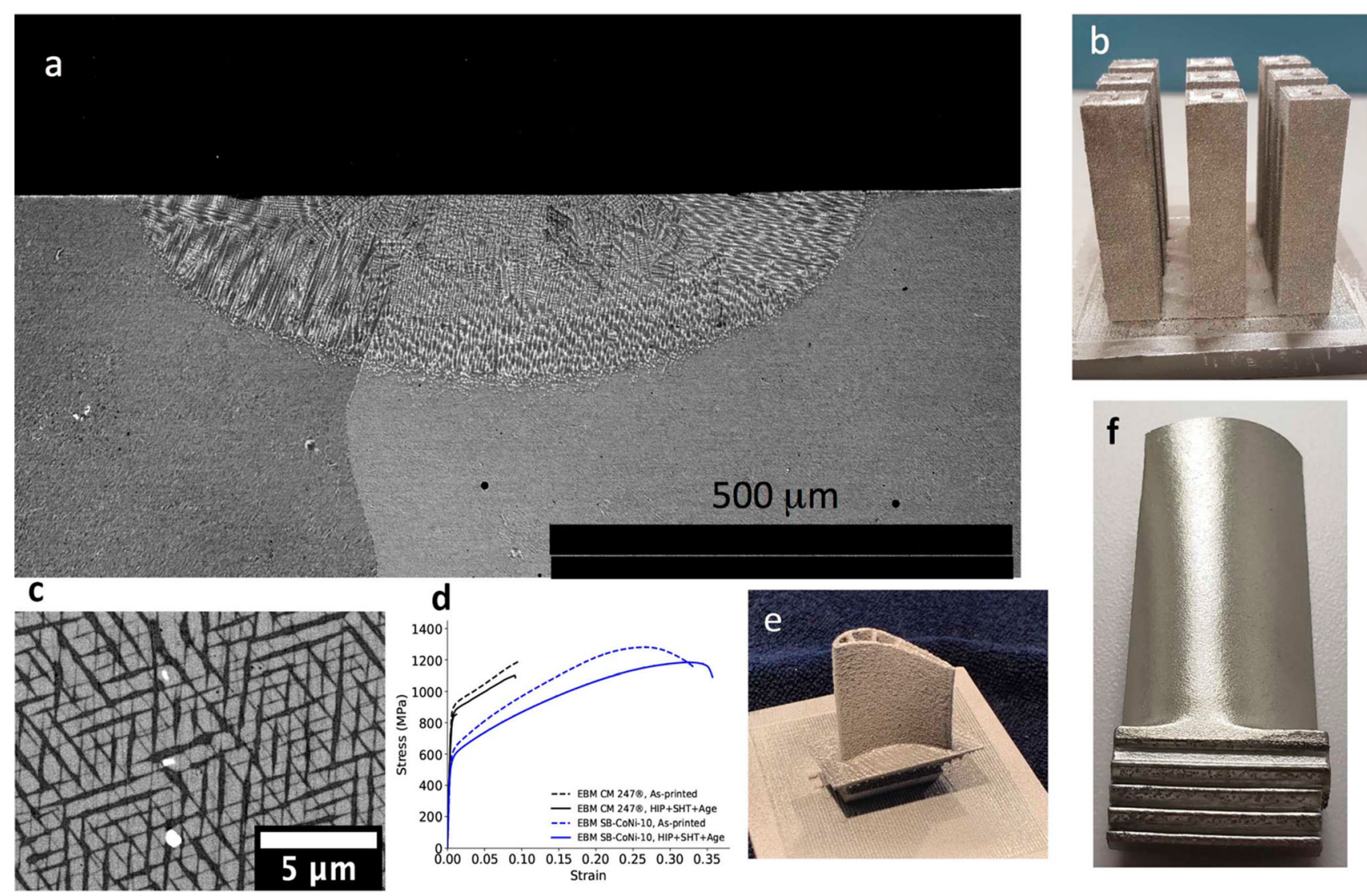

Fig. 10-Deign of a printable Co-Ni-base alloy SB-CoNi-10. (a) High-angle boundary propagating through an electron beam track melt pool without local cracking along the boundary, $(b)$ bars printed with varying print parameters by E-PBF, $(c)$ fine-scale $\mathrm{L}_{2}$ precipitates in samples after electron beam printing followed by HIP and heat treatment, (d) room temperature tensile properties of CoNi-SB10 compared to CM247 in the as-printed and HIP + heat-treated conditions, $(e)$ blade-like thin wall samples printed by electron beam, and $(f)$ laser powder bed processes. Note the exceptional surface (less than one-micron roughness) of the laser powder bed printed sample. Images courtesy of S. Murray (UCSB), M. Kirka (Oak Ridge National Laboratory) and S. Forsik (Carpenter Technology). 
only one batch of powder being produced and standard ranges of printing parameters being employed in both L-PBF and E-PBF. ${ }^{129]}$

Given the combination of a high dimensional alloy design space and the complexity of the physics of PBF printing, suites of predictive tools will greatly enhance our ability to design "printable" alloys. ${ }^{[142]}$

\section{Limitations}

A significant gap in the infrastructure for alloy design for AM exists in the ability to incorporate alloy-specific information into print process models. This is not surprising, given that the length-scales span from the atomistic that controls fundamental alloy properties and thermodynamics, to the melt pool scale (hundreds of microns) where solidification phenomena occur, to the macroscale (thousands of printed layers) where grain structure, defects, residual stresses, and the ultimate mechanical properties are controlled. Kinetic considerations are also needed. Continued development of modeling suites across both the processing and property space will greatly enhance additive alloy development.

\section{H. Challenges and Future Directions}

The previous case studies and examples highlighted in Section II have demonstrated that existing foundational physical metallurgy knowledge, as well as emerging computational modeling tools can provide a platform for alloy design for AM. However, there are many knowledge gaps that challenge the coupling of alloy design to AM processing of advanced engineering components, including accurate descriptions of the thermo-mechanical-chemical boundary conditions typical to AM, as well as fundamentals of interphase instability between plasma-gas, gas-liquid, liquid-solid and solid-solid phases. In this section, these challenges are discussed in more detail, along with emerging tools that can fill these knowledge gaps. Potential directions are outlined briefly and some examples are provided.

\section{Characterization of Boundary Conditions during AM}

Based on recent publications, it is indeed clear that thermal-mechanical-chemical boundary conditions that dictate defect formation and liquid-solid and solid-state transformations are interrelated between the geometry of the component (e.g., prismatic shapes or complex internal channels, cavities), chamber conditions (e.g., partial pressure of oxygen), material feedstock and delivery (e.g., recycling, powder raking ${ }^{[143]}$ ), process parameters (e.g., power, speed, focus, scan strategy), and post-processing (e.g., machining, heat treatment, HIP). Therefore, it is imperative that we track these conditions for given AM processes with existing diagnostics, or by augmenting AM machines with commercial tools. These diagnostics ${ }^{[144,145]}$ can be sophisticated and expensive (e.g., custom made high-speed, high-resolution infrared thermography $)^{[146]}$ or optical surface measurements based on video cameras ${ }^{147]}$ or laser confocal microscopes ${ }^{[148,149]}$ ). For example, Foster et al. ${ }^{[150]}$ used surface roughness measurements to demonstrate the merging of subsequent weld beads with nearby scans, which may affect porosity formation across the build. The case for sensing all parameters (e.g., powder distribution, temperature, surface roughness, displacement), including chemical sensing, is made by Mazumder ${ }^{[151]}$ in his paper that describes the concept of "certify as you build." The local changes in chemistry within a geometry may lead to large-scale differences in microstructures and properties, which are well documented in the welding metallurgy literature. ${ }^{[152,153]}$

\section{J. Concurrent Geometry and Alloy Design}

As mentioned earlier, the qualification of components made by AM processes cannot ignore the role of geometries in dictating the local thermo-mechanical conditions. This close coupling of the geometry and AM was demonstrated by Yoder et al. ${ }^{[154]}$ The authors adopted a concept being followed by industry for qualification, i.e., printing of tensile coupons surrounding the real part and using the test data as a way to qualify the parts.

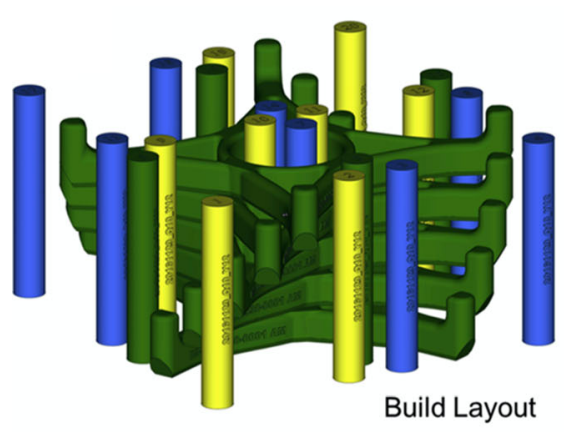

(a)

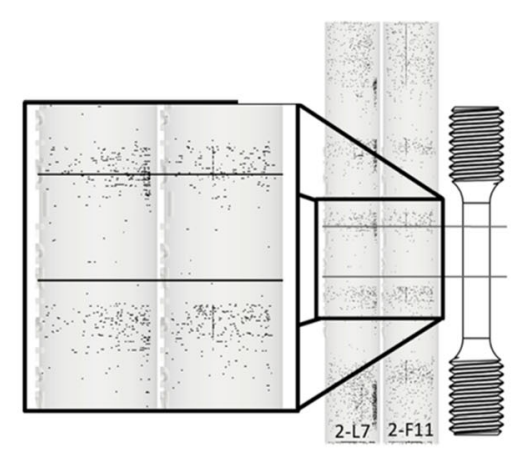

(b)

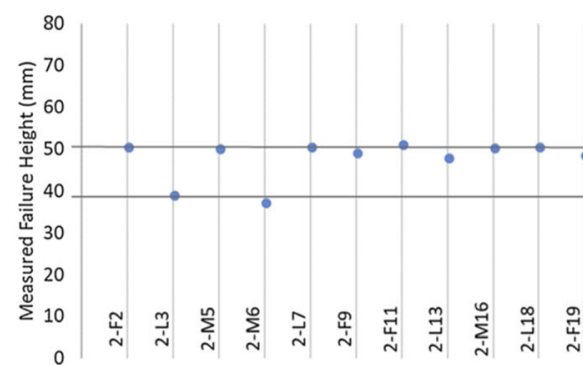

(c)

Fig. 11-Correlation of geometries to properties of Ti6Al4V fixtures made by the E-PBF process: $(a)$ build layout of the fixture with placement of tensile samples around the component; (b) NIR images were interpreted to identify the locations of pores with reference to tensile test geometry; and $(c)$ measured locations of the failure that correlated with higher concentration porosity regions. Images were reproduced with permission from Ref. [154]. 


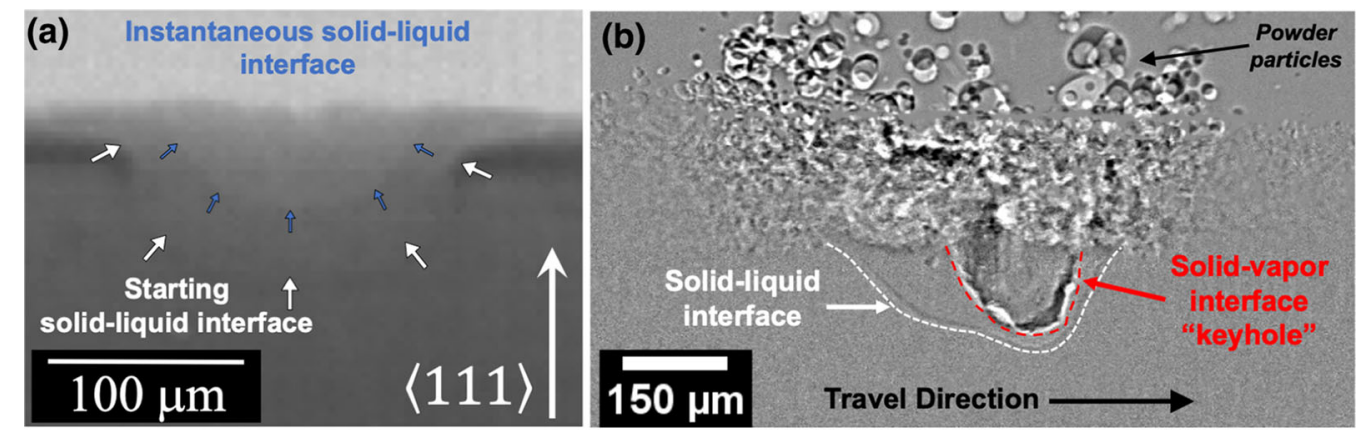

(c) Travel direction $\rightarrow \quad$ In-situ radiograph

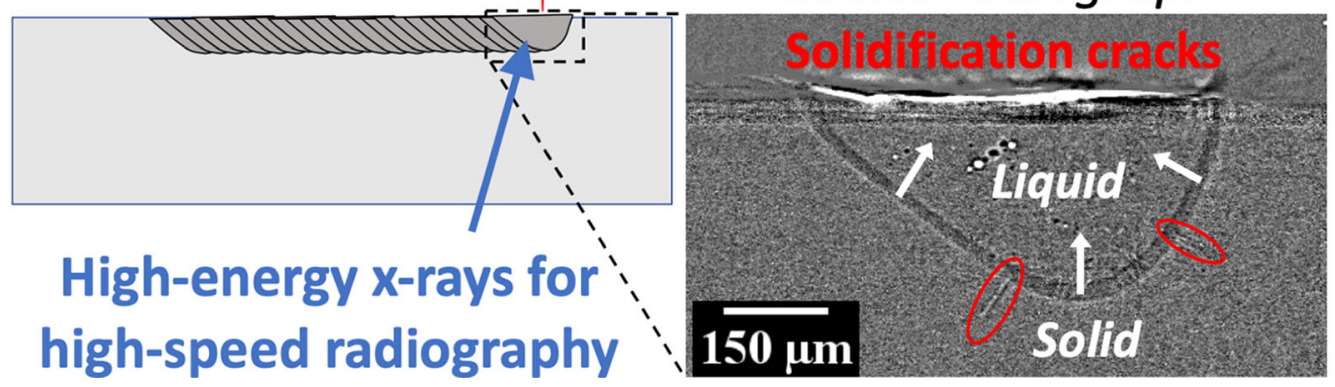

Fig. 12-(a) In-situ synchrotron X-ray image of a laser spot melt during solidification of a Ni-6.6Al-1.9Mo (wt pct) alloy $\langle 111\rangle$ single crystal substrate ( $104 \mathrm{~W}, 1 \mathrm{~ms}$ spot), highlighting the progression of the solid-liquid interface, $(b)$ synchrotron x-ray image of a pure Al substrate with a pure Al powder layer during laser raster melting and solidification $(416 \mathrm{~W}, 1 \mathrm{~m} / \mathrm{s}$ rater), highlighting the solid-liquid interface and the solid-vapor interface "keyhole," and $(c)$ a schematic diagram of a laser melting raster and a synchrotron X-ray image of wrought $6061 \mathrm{Al}(520$ $\mathrm{W}, 0.5 \mathrm{~m} / \mathrm{s}$ raster), highlighting the solid-liquid interface and the formation of solidification cracks. Courtesy of J. Klemm-Toole, A. Saville, J. Shin, B. Rodgers, C. Johnson, G. Becker, B. Ellyson, Y. Guo, B. Milligan, J. Copley, and A. Clarke (Colorado School of Mines), A. Polonsky, K. Pusch, B. Yahata, J. Rossin, and T. Pollock (University of California Santa Barbara), and K. Fezzaa, T. Sun, and N. Parab (Advanced Photon Source, Argonne National Laboratory).

During the build process of a Ti-6Al-4V (wt pct) alloy fixture geometry (Figure 11a), the quality of the build was monitored in every layer using near-infrared radiation (NIR) images. With these images, the authors were able to identify the locations at which higher tendencies for the formation of porosities exist (Figure 11b). Interestingly, these locations correlated with the geometrical design used in that build. The porosities formed where there was an abrupt transition in the geometry being printed. These abrupt transitions for given processing conditions lead to large changes in layer processing time, i.e., changes in thermal signatures. Interestingly, all the tensile samples failed (Figure 11c) at these locations where porosities formed. This example illustrates that any alloy design should be accompanied concurrently with geometrical and process design too, where computational modeling may prove to be helpful. ${ }^{[155]}$ It is important to note that solid bars of simple shapes printed next to a geometrically complex component may experience a very different thermal environment compared to the printed part.

\section{K. In-situ Probing of Phases and Interfaces under Simulated AM Conditions}

Geometry-alloying-processing-structure-property-performance relationships are clearly important to AM. Extensive knowledge of the dynamic conditions that dictate the phases and their stabilities as a function of temperature, stress, and composition ${ }^{[156]}$ is needed to design microstructures and properties created by AM. The need exists to probe these interfaces under the highly dynamic conditions that exist during AM by in-situ characterization of simulated AM. Novel tools and unique probes available at national user facilities are affording unprecedented opportunities to study phase transformations and microstructural development during simulated AM. For example, phenomena like solidification, solid-state phase transformations, keyholing, pore formation, melt pool dynamics, powder spreading, and specific AM processes like laser powder bed fusion (L-PBF) have been explored with in-situ $\mathrm{x}$-ray imaging and diffraction. ${ }^{[100,109,157-171]}$ Figure 12 highlights example synchrotron $\mathrm{x}$-ray imaging of melt pool and solidification dynamics obtained from Ni-base and $\mathrm{Al}$ alloys melted via the L-PBF AM simulator at the Advanced Photon Source at Argonne National Laboratory. Figure 12a highlights the position of the solid-liquid interface during solidification after laser spot melting of a Ni-6.6Al-1.9Mo (wt pct) $\langle 111\rangle$ single crystal substrate. Figure 12(b) shows a pure Al substrate with a pure $\mathrm{Al}$ powder layer during laser raster melting. Powder particle dynamics during melting can be visualized, in addition to the position of the solid-liquid interface during solidification and the solid-vapor interface "keyhole" that forms. Figure 12(c) schematically shows a laser melt raster, along with an in-situ x-ray image that reveals not only the solid-liquid interface 
position during solidification, but also the formation of solidification cracks (i.e., defects) in a wrought $6061 \mathrm{Al}$ substrate.

In addition to in-situ x-ray imaging (and diffraction) of simulated AM, dynamic transmission electron microscopy (DTEM) provides unprecedented spatial and temporal (tens of nanometers and nanoseconds) resolutions to visualize rapid solidification dynamics. ${ }^{[172-178]}$ These in-situ techniques are enabling new understanding and insights into melt pool and solidification dynamics relevant to AM, and are providing real-time, quantitative measurements of important physical phenomena to inform solidification and process models [e.g., 179-182], including the integration of multiscale process-structure-propertyperformance models for AM. ${ }^{[183]}$

Although experiments such as these provide a wealth of time-resolved information, significant opportunity exists to refine and automate the associated data post processing (e.g., image analysis) to realize un-biased, quantitative information. Improved modeling of thermal gradients and model calibration are also needed. In particular, deeper understanding of nucleation is warranted, which remains experimentally challenging to study. Additionally, AM is a highly transient process, and the role of melt pool dynamics (e.g., fluid flow and convection) and local heat and solute transport on microstructure selection should not be ignored. Coupled with in-situ experiments, complementary ex-situ characterization also provides more comprehensive understanding of microstructure and defect development as a function of processing and the local conditions experienced during AM, enabling design of defect-resistant compositions.

\section{Ex-situ Probing of Phases and Interfaces}

As noted previously, in addition to solidification, subsequent solid-state phase transformations are expected to have significant impacts on properties, such as mechanical anisotropy. Informed by earlier work on texture evolution in Ti-6Al-4V (wt pct), ${ }^{[99]}$ we are currently exploring the role of scan strategy and build height on microstructure and bulk and local texture evolution with neutron diffraction and complementary techniques.

Figure 13 highlights example texture results obtained with neutron diffraction from electron beam melted Ti-6Al-4V (wt pct) built with spot melt and raster scan strategies at different build heights. Cubes were produced with innovative beam scanning strategies (i.e., Dehoff and Random spot melts) and traditional raster scanning using the Electron-Powder Bed Fusion (E-PBF) process. In the Dehoff scan strategy, the beam deposits energy in a regular array with intermittent skipping until all the space is visited by the beam. By controlling the beam-on time, the amount of total energy deposited per layer can be modified. With this approach, it is quite possible to modify thermal gradient at different locations during the build. The methodologies behind this strategy have been discussed in depth before. ${ }^{[4]}$ The random scan strategy follows the same approach in filling the space; however, the sequence of visiting every pixel is random for given layer. The differences in scan strategy are schematically shown in Figures 13(a), (b), and (c). Significant texture variations are not observed as a function of build height with neutron diffraction, but texture variations are observed with differences in scan strategy. Although not shown here, texture development has been linked to important microstructural characteristics that provide insights into microstructural control during AM with processing variations.

In addition to these new results, various recent publications have focused on the evolution of texture during AM and also after the post-processing. ${ }^{[185]}$ From this work, insights into bulk vs local texture development in AM builds and processing and quantification of AM texture components are underway, paving the way for follow-on analyses and experiments. Correlations between the observed textures, microstructural evolution, and the local processing conditions are also being pursued.

\section{Post-Processing and Qualification}

A number of challenges exist in terms of designing alloys that are not only amenable to printing, but can also be post-processed. While hot isostatic pressing is often performed on post-printed materials to heal porosity, ideally this slow and expensive step would be eliminated by controlling porosity during the build process. Thermal treatments that are conducted following printing often induce recrystallization, due to the high levels of residual stresses that build up during printing. ${ }^{[186-188]}$ Detailed studies of recrystallization behavior as a function of print process conditions, particularly in more complex shaped components, have not yet been conducted. Small amounts of second phases (carbides, oxides, nitrides) might intentionally be designed into alloys for the purpose of controlling recrystallization and grain growth.

Beyond the in-situ diagnostics discussed above, non-destructive evaluation (NDE) approaches for detecting defects and undesirable microstructural features need to be more fully developed. Micro-computed tomography scans $(\mu \mathrm{CT})$ can be used to inspect for pores in printed structures, ${ }^{[189]}$ but their resolution is limited in terms of detection of finer scale porosity $(<<100 \mu \mathrm{m}$ and dependent on section thickness) that could, for example, influence fatigue properties. Machine learning for defect detection may also prove useful. With respect to grain structures, which are alloy sensitive and can vary from columnar to equiaxed, depending on the print conditions used and local processing variations, inspection approaches are much more limited. High-intensity ultrasound ${ }^{[190]}$ or resonant ultrasound spectroscopy, which can detect anisotropic grain structures, could provide a means to track part to part variability in grain structure, particularly if combined with "forward models" of the expected grain structure. ${ }^{[191,192]}$

Given that the qualification of new alloys for conventional processing is well known to be a major challenge, ${ }^{[193]}$ the qualification of new alloys for additive 


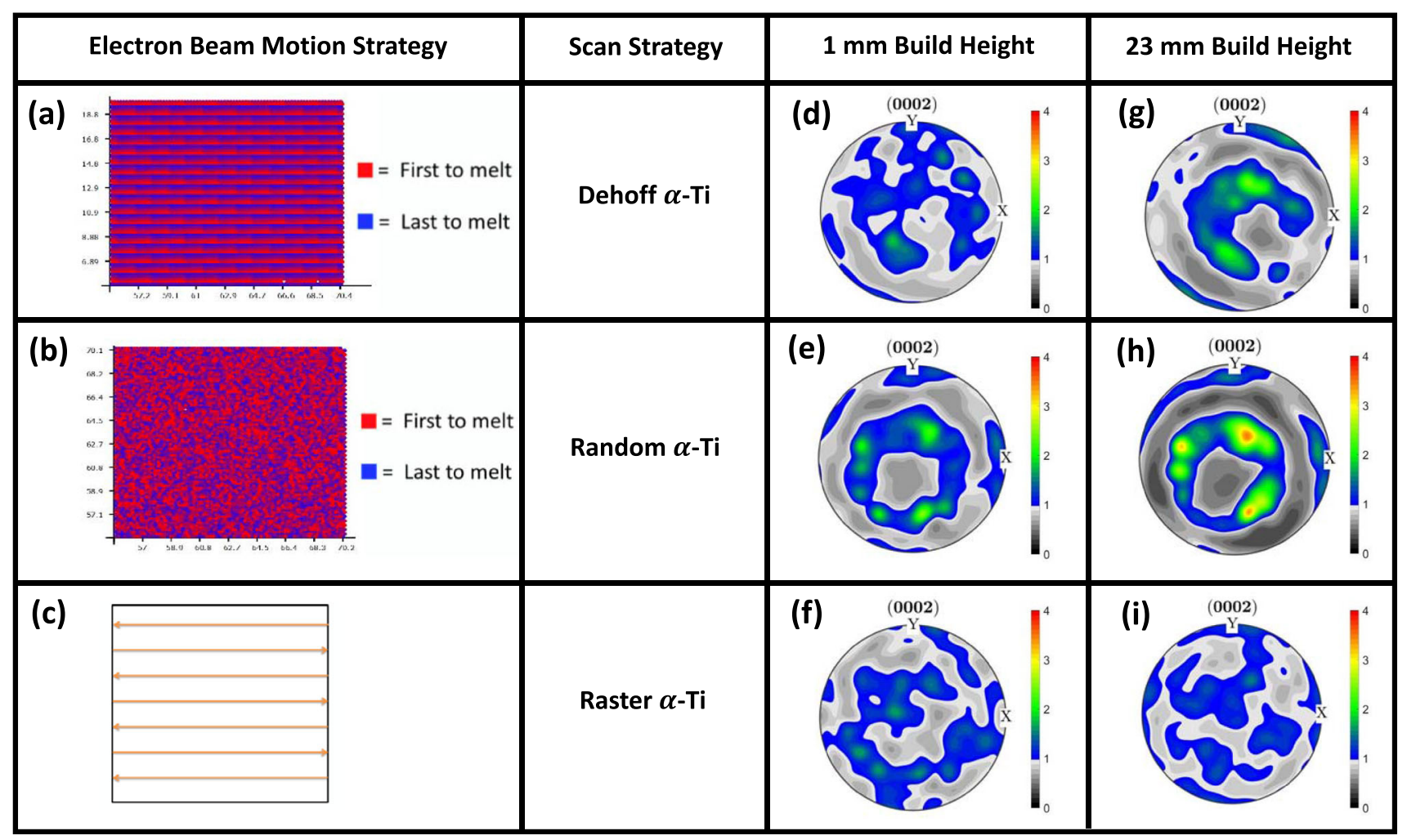

Fig. 13-Role of beam scan strategy on texture of $\alpha$ (HCP) (0002) in the XY plane of Ti-6Al-4V (wt pct) cube builds: different scanning strategies adopted: $(a)$ Dehoff; $(b)$ Random; and $(c)$ Raster mode; texture close to the substrate: $(d)$ Dehoff; $(e)$ Random and $(f)$ Raster mode. Note the asymmetric distribution of the (0002) poles around the build direction. Texture close to the top of the build: $(g)$ Dehoff; $(h)$ Random, and (i) Raster mode. Courtesy of A.I. Saville, J. Klemm-Toole, K.D. Clarke and A.J. Clarke (Colorado School of Mines), S. Vogel (Los Alamos National Laboratory), A. Creuziger and J. Benzing (National Institute of Standards and Technology), A. Pilchak (Air Force Research Laboratory), S. Kumar, S.S. Babu and P. Nandwana (UT and Oak Ridge National Laboratory). ${ }^{[184]}$

manufacturing will be similarly challenging. Being inherently digital, additive manufacturing lends itself to digital thread-type approaches for qualification, ${ }^{[194,195]}$ as well as uncertainty quantification. ${ }^{[196]}$ Given that protocols for the qualification of new additive processing paths are just now being developed, the inclusion of new alloys early in the process will enhance the probability that alloys that match the unique, new processing paths afforded by AM that reach maturity.

\section{N. Summary and Conclusions}

Additive manufacturing of metals and alloys through powder bed fusion (PBF) technology has opened up new opportunities for the design of alloys matched to AM processes to arrive at site-specific, tailored microstructures and properties for aerospace, energy, and biomedical applications. In this perspective paper, some opportunities for alloy tailoring and design for AM are highlighted through recent examples of powder manipulation and the use of inoculants/nucleants and the purposeful control of metallurgical aspects related to solidification and solid-state phase transformations. Foundational knowledge gained from conventional manufacturing processes like casting, welding, and powder metallurgy can be extended and built upon to control the interface conditions related to plasma, gas, liquid, and solid phases under spatially and temporally varying thermo-mechanical-chemical conditions that prevail in laser- and electron beam-based PBF technologies. Three case studies are presented that demonstrate the potential for thoughtful alloying and processing to significantly impact microstructural development under AM conditions. In the first example, the in-situ formation of carbo-nitrides in the liquid was triggered by manipulating the environmental conditions with respect to the melt pool, leading to fine-scale microstructures and improved properties. In the second case study, the CET boundaries during solidification and $\gamma^{\prime}$ phase fractions were designed with composition variations in nickel-base superalloys. The E-PBF process was used to validate the predictions and alloy design strategies, highlighting the potential for alloys to match to the unique processing conditions encountered during AM. In the third example, high-throughput computational tools and combinatorial experiments were used to arrive at an optimum $\mathrm{Co}-\mathrm{Ni}$ superalloy, with limited experimental testing. E-PBF processing, followed by HIPing and heat treatment, resulted in fine-scale $\mathrm{L}_{2}$ precipitates and the creation of desirable microstructures and properties. Moving forward, we recognize the need to fundamentally understand geometryalloying-processing-property-performance relationships 
unique to AM, need for predictive tools, and opportunities for in-situ monitoring to fundamentally understand AM.

\section{ACKNOWLEDGMENTS}

The authors (TP, AC, and SB) acknowledge the support of the US Department of the Navy, Office of Naval Research under ONR award number N00014-18-1-2794. Any opinions, findings, and conclusions or recommendations expressed in this material are those of the author(s) and do not necessarily reflect the views of the Office of Naval Research. This research used resources of the Advanced Photon Source, a U.S. Department of Energy (DOE) Office of Science User Facility operated for the DOE Office of Science by Argonne National Laboratory under Contract No. DE-AC02-06CH11357. This work was performed, in part, at the Los Alamos Neutron Science Center (LANSCE), a NNSA User Facility operated for the U.S. Department of Energy (DOE) by Los Alamos National Laboratory (Contract 89233218CNA000001). SB acknowledges support from the U.S. Department of Energy, Office of Energy Efficiency and Renewable Energy, Advanced Manufacturing Office, under contract DE-AC05-00OR22725 with UT-Battelle, LLC. This manuscript has been authored by UT-Battelle, LLC under Contract No. DE-AC0500OR22725 with the U.S. Department of Energy. The United States Government retains and the publisher, by accepting the article for publication, acknowledges that the United States Government retains a nonexclusive, paid-up, irrevocable, world-wide license to publish or reproduce the published form of this manuscript, or allow others to do so, for United States Government purposes. The Department of Energy will provide public access to these results of federally sponsored research in accordance with the DOE Public Access Plan (https://www.energy.gov/downloads/doe-p ublic-access-plan).

\section{REFERENCES}

1. ASTM/ISO 52900:2015(E): Standard Terminology for Additive Manufacturing - General Principles and Terminology, 2016.

2. B. Dutta, S.S. Babu, and B.H. Jared: Science and Technology and Applications of Metals in Additive Manufacturing, Elsevier, Amsterdam, 2019.

3. D.D. Gu, W. Meiners, K. Wissenbach, and R. Poprawe: Int. Mater. Rev., 2012, vol. 57, pp. 133-64.

4. S. Das, D.L. Bourell, and S.S. Babu: MRS Bull., 2016, vol. 41, pp. 729-41.

5. W.J. Sames, F.A. List, S. Pannala, R.R. Dehoff, and S.S. Babu: Int. Mater. Rev., 2016, vol. 61, pp. 315-60.

6. T. DebRoy, H.L. Wei, J.S. Zuback, T. Mukerjee, J.W. Elmer, J.O. Milewski, A.M. Beese, A. Wilson-Heid, A. De, and W. Zhang: Prog. Mater. Sci., 2018, vol. 92, pp. 112-224.

7. M. Gebler, A.J.M. Schoot Uiterkamp, and C. Visser: Energy Policy, 2014, vol. 74, pp. 158-67.

8. K. Kellens, M. Baumers, T.G. Gutowski, W. Flanagan, R. Lifset, and J.R. Duflou: J. Ind. Ecol., 2017, vol. 21, pp. S49-68.

9. D. Herzog, V. Sevda, K. Wyciskm, and C. Emmelman: Acta Mater., 2016, vol. 117, pp. 371-92.
10. B. Vrancken, L. Thijis, J.P. Kruth, and J. Van Humbeeck: $J$. Alloys Compd., 2012, vol. 541, pp. 177-85.

11. E. Brandl, U. Heckenberger, V. Holzinger, and D. Buchbinder: Mater. Des., 2012, vol. 34, pp. 159-69.

12. J.J. Lewandowski and M. Siefi: Ann. Rev. Mater. Res., 2016, vol. 46, pp. 151-86.

13. W. Xu, M. Brandt, S. Sun, J. Elambasseril, Q. Liu, K. Latham, K. Xia, and M. Qian: Acta Mater., 2015, vol. 85, pp. 74-84.

14. Q.B. Jia and D.D. Gu: J. Alloys Compd., 2014, vol. 585, pp. 713-21.

15. D.H. Ding, X.Z. Pan, D. Cuiuri, and H.J. Li: Int. J. Adv. Manuf. Technol., 2015, vol. 81, pp. 465-81.

16. Y.L. Li and D.D. Gu: Mater. Des., 2014, vol. 63, pp. 856-67.

17. S. Biamino, A. Penna, U. Ackelid, S. Sabbadini, O. Tassa, P. Fino, M. Pavese, P. Gennaro, and C. Badini: Intermetallics, 2011, vol. 19, pp. 776-81.

18. C. Korner: Int. Mater. Rev., 2016, vol. 5, pp. 361-77.

19. T. Niendorf, S. Leuders, A. Riemer, H.A. Richard, T. Troster, and D. Schwarze: Metall. Mater. Trans. B, 2013, vol. 44, pp. $794-96$

20. D. Manfredi F. Calingnano M. Krishnan R. Canali E.P. Ambrosio E. Atzeni : Materials, 2013, vol. 6, pp. 85669

21. R. Wauthle, B. Vrancken, B. Beynaerts, K. Jorissen, J. Schrooten, J.P. Kruth, and J. Van Humbeeck: Addit. Manuf., 2015, vol. 5, pp. 77-84.

22. C.Z. Yan, L. Hao, A. Hussein, and P. Young: J. Mech. Behav. Biomed. Mater., 2015, vol. 51, pp. 61-73.

23. C. Kamath, B. El-Dahser, G.F. Gallegos, W.E. King, and A. Sisto: Int. J. Adv. Manuf. Technol., 2014, vol. 74, pp. 65-78.

24. S. Gorsse, C. Hutchinson, M. Goune, and R. Banerjee: Sci. Technol. Adv. Mater., 2017, vol. 18, pp. 584-610.

25. S.Y. Liu, and Y.C. Shin, Mater. Des., 2019, Vol. 164, \#107552.

26. W. Xu, E.W. Lui, A. Pateras, M. Qian, and M. Brandt: Acta Mater., 2017, vol. 125, pp. 390-400.

27. Y.S. Hedberg, B. Qiian, Z.F. Shen, S. Virtanen, and I.O. Wallinder: Dent. Mater., 2014, vol. 30, pp. 525-34.

28. A. Hehr, J. Wenning, K. Terrani, S.S. Babu, and M. Norfolk: JOM, 2017, vol. 69, pp. 485-490, https://doi.org/10.1007/s11837016-2205-6.

29. A.R. Moustafa, R.B. Dinwiddie, A.E. Pawlowski, D.A. Splitter, A. Shyam, and Z.C. Cordero: Addit. Manuf., 2018, vol. 22, pp. 223-29.

30. A. Plotkowski, K. Sisco, S. Bahl, A. Shyam, Y. Yang, L. Allard, P. Nandwana, A. Marquez Rossy, and R.R. Dehoff: Acta Mater., 2020, vol. 196 , pp. $595-608$.

31. J. Haynes: "Additive manufacturing for liquid rocket engines - large Scale and Process Monitoring," presented at additive manufacturing for defense and government symposium, July 14, 2017, Distribution A: Approved for Public Release; Case Number 88ABW-2017-388, Cleared on 10 July 2017, reproduced with permission.

32. F. Bechmann: Met. Powder Rep., 2014, vol. 69, pp. 37-40.

33. N. Seto, S. Katayama, and A. Matsunawa: Weld. Int., 2001, vol. 15 , pp. 191-202.

34. T. McFalls, The effect of hydrogen on gas porosity in Laser Powder Bed Fusion of AlSi10Mg. Master's Thesis, University of Tennessee, TN, https://trace.tennessee.edu/utk_gradthes/5174.

35. G.M. Evans and N. Bailey: Metallurgy of Basic Weld Metal, Elsevier, Amsterdam, 1997.

36. P. Fauchais, G. Montavon, and G. Bertrand: J. Therm. Spray Technol., 2010, vol. 19, pp. 56-80.

37. R. de Oro Calderon, C. Gierl-Mayer, and H. Danninger: Powder Metall., 2017, vol. 60, pp. 86-96.

38. L.E. Murr: Addit. Manuf., 2015, vol. 5, pp. 40-53.

39. X. Lou and D. Gandy: JOM, 2019, vol. 71, pp. 2834-36.

40. Welding consumables standards, https://www.iso.org/ics/25.160. $20 / \mathrm{x} /$.

41. J.J. Lewandowski and M. Seifi: Annu. Rev. Mater., 2016, vol. 46, pp. 151-86.

42. S.W. Williams, A.C. Addison, J. Ding, G. Pardal, and P. Colgrove: Mater. Sci. Technol., 2016, vol. 32, pp. 641-47.

43. B. Shassere, D. Greeley, A. Okello, M.M. Kirka, P. Nandwana, and R.R. Dehoff: Metall. Mater. Trans., 2018, vol. 49, pp. $5107-117$. 
44. A. Polonsky, M.P. Echlin, W.C. Lenthe, R.R. Dehoff, M.M. Kirka, and T.M. Pollock: Mater. Charact., 2018, vol. 143, pp. 171-81.

45. M.M. Kirka, K. Unocic, N. Raghavan, F. Medina, R.R. Dehoff, and S.S. Babu: JOM, 2016, vol. 68, pp. 1012-20.

46. W.E. King, A.T. Anderson, R.M. Ferencz, N.E. Hodge, C. Kamath, S.A. Kairallah, and A.M. Rubenchik, Appl. Phys. Rev., 2015, vol. 2, \#041304.

47. M. Markl and C. Korner: Ann. Rev. Mater. Res., 2016, vol. 46, pp. 93-123.

48. N. Raghavan, R. Dehoff, S. Pannala, S. Simunovic, M. Kirka, J. Turner, N. Carlson, and S.S. Babu: Acta Mater., 2016 , vol. 112, pp. 303-14.

49. E.J. Schwalbach, S.P. Donegan, M.G. Chapman, K.J. Chaput, and M.A. Groeber: Addit. Manuf., 2019, vol. 25, pp. 485-98.

50. Y.S. Lee, M.M. Kirka, J. Ferguson, and V.C. Paquit, Addit. Manuf., 2020, vol. 32,\#101031.

51. D. Adair, M.M. Kirka, and D. Ryan, Proceedings of the International Conference on Turbo Exp: Power for Land, Sea and Air, 2019, ASME, vol. 58677, pp. V006T24A012.

52. J. Dawes, R. Bowerman, and R. Trepleton: Johnson Matthey Tech. Rev., 2015, vol. 59, pp. 243-56.

53. I.E. Anderson, E.M.H. White, and R.R. DeHoff: Curr. Opin. Solid State Mater. Sci., 2018, vol. 12, pp. 8-15.

54. L. Koehler: ASM Handbook Volume 7: Powder Metallurgy, ASM International, 2015, pp. 673-681.

55. B. Poorganji, E. Ott, R. Kelkar, A. Wessman, and M. Jamshidinia: JOM, 2020, vol. 72, pp. 561-76.

56. Integrated Computational Materials Engineering: A Transformational Discipline for Improved Competitiveness and National Security. National Research Council, ISBN: 0-309-12000-4, 2008.

57. T.M. Pollock and A. Van der Ven: The evolving landscape for alloy design $M R S$ Bull., 2019, vol. 44, pp. 238-44.

58. J.H. Panchal, S.R. Kalidindi, and D.L. McDowell: Comput. Aided Des., 2013, vol. 45, pp. 4-25.

59. J.C. Wang, Y.J. Liu, P. Qin, S.X. Lian, T.B. Sercombe, and L.C. Zhang: Mater. Sci. Eng. A, 2019, vol. 760, pp. 214-24.

60. E. Cakmak, N. Sridharan, S. Venkatakrishna, H. Bilheux, L. Santodnato, A. Shyma, and S.S. Babu: Metall. Mater. Trans. A., 2018, vol. 49, pp. 5035-41.

61. M.P. Echlin, M. Straw, S. Randolph, J. Filevich, and T.M. Pollock: Mater. Charact., 2015, vol. 100, pp. 1-12.

62. J.H. Boswell, D. Clark, W. Li, and M. Attallah, Mater. Des., 2019, vol. 174, p. \#107793.

63. A. Seidel, T. Finaski, A. Straubel, H. Wendrock, T. Maiwald, M. Riede, E. Lopez, F. Brueckner, and C. Leyens: Metall. Mater. Trans., 2018, vol. 49A, p. 3812.

64. N.J. Harrison, I. Todd, and K. Mumtaz: Acta Mater., 2015, vol. 94, pp. 59-68.

65. S.S. Babu, N. Raghavan, J. Raplee, S.J. Foster, C. Frederick, M. Haines, R. Dinwiddie, M.M. Kirka, A. Plotkowski, Y. Lee, and R.R. Dehoff: Metall. Mater. Trans. A., 2018, vol. 49, pp. $3764-80$.

66. J.H. Martin, B.D. Yahata, J.M. Hundley, J.A. Mayer, T.A. Schadler, and T.M. Pollock: Nature, 2017, vol. 549, pp. 365-69.

67. D. Qiu, D. Zhang, M.A. Easton, D.H. St. John, and M.A. Gibson: Metall. Mater. Trans., 2018, vol. 49A, pp. 1444-49.

68. J.C. Villafuerte, H.W. Kerr, and S.A. David: Mater. Sci. Eng. A, 1995, vol. A194, pp. 187-91.

69. D. Carluccio, M. Bermingham, Y. Zhang, D. St. John, K. Yang, P. Rometsch, X. Wu, and M. Dargusch: J. Man. Proc., 2018 , vol. 35 , p. 715 .

70. X.P. Li, G. Ji, Z. Chen, A. Addad, Y. Wu, H.W. Wang, J. Vleugels, J. Van Humbeeck, and J.P. Kruth: Acta Mater., 2017, vol. 129, pp. 183-93.

71. F. Palm, and K. Schmidtke, Trends in Welding Research, ASM International, 2013, pp. 108-116.

72. J.S. Neuchterlein, and J.J. Iten, Reactive Additive Manufacturing, US Patent 20160271878 A1, Priority 2015-03-17, Published 2016-10-22.

73. F. Medina, Reducing metal alloy powder costs for use in powder bed fusion additive manufacturing: improving the economics for production, PhD Thesis, University of Texas and El Paso, 2013, https://search.proquest.com/docview/1501958100.
74. J.I. Arrizubieta, O. Ukar, M. Ostolaza, and A. Mugica, Metals, 2020, vol. 10, \#261, https://doi.org/10.3390/met10020261.

75. S.A. David and J.M. Vitek: Int. Mater. Rev., 1989, vol. 34, pp. 213-45.

76. R. Trivedi and W. Kurz: Int. Mater. Rev., 1994, vol. 39, pp. 49-74.

77. J. Dantzig and M. Rappaz: Solidification, 2nd ed., EPFL Press, Lausanne, 2017.

78. S.S. Babu, S.A. David, J.-W. Park, and J.M. Vitek: Sci. Technol. Weld. Join., 2004, vol. 9, pp. 1-12.

79. M. Rappaz, S.A. David, J.M. Vitek, and L.A. Boatner: Metall. Trans. A, 1989, vol. 20A, p. 1125.

80. M. Rappaz, S.A. David, J.M. Vitek, and L.A. Boatner: Metall. Trans. A, 1990, vol. 21A, p. 1767.

81. S. Kou: Welding Metallurgy, 2nd ed., Wiley-Interscience, Hoboken, 2012.

82. A. Plotkowski, M.M. Kirka, and S.S. Babu: Addit. Manuf., 2017, vol. 18 , pp. 256-68.

83. N. Raghavan, A. Plotkowski, R.R. Dehoff, J.A. Turner, M.K. Kirka, and S.S. Babu: Acta Mater., 2017, vol. 140, pp. $375-87$.

84. S.S. Babu, J.W. Elmer, J.M. Vitek, and S.A. David: Acta Mater., 2002, vol. 50, pp. 4763-81.

85. S. Fukumoto and W. Kurz: ISIJ Int., 1997, vol. 37, pp. 677-84.

86. Y.S. Lee, M. Nordin, S.S. Babu, and D.F. Farson: Metall. Mater. Trans. B, 2014, vol. 45, pp. 1520-29.

87. W. Sames, K. Unocic, R.R. Dehoff, T. Lolla, and S.S. Babu: J. Mater. Res., 2014, vol. 29, pp. 1920-30.

88. J. Draxler, J. Edeberg, J. Andersson, and L.-E. Lindgren: Weld. World, 2019, vol. 63, pp. 1883-1901.

89. J.-W. Park, J.M. Vitek, S.S. Babu, and S.A. David: Sci. Technol. Weld. Join., 2004, vol. 9, pp. 472-82.

90. Z. Feng, T. Zacharia, and S.A. David: Weld. J., 1997, vol. 11, pp. $470 \mathrm{~s}-83 \mathrm{~s}$

91. M. Rappaz, J.-M. Drezet, and M. Germaud: Metall. Mater. Trans. A, 1999, vol. 30A, pp. 449-55.

92. Y. Lee, M. Kirka, S. Kim, N. Sridharan, A. Okello, R.R. Dehoff, and S.S. Babu: Metall. Mater. Trans. A, 2018, vol. 49, pp. $5065-79$

93. P. Kürnsteiner, P. Bajaj, A. Gupta, M.B. Wilms, A. Weisheit, X. Li, C. Leinenbach, B. Gault, E.A. Jägle, D. Raabe, Addit. Manuf., 2020, vol. 32, \#100910.

94. S.M. Kelly and S.L. Kampe: Metall. Mater. Trans. A, 2004, vol. 35, pp. 1861-67.

95. S.M. Kelly and S.L. Kampe: Metall. Mater. Trans. A, 2004, vol. 35, pp. 1869-79.

96. K.T. Makiewicz, Development of simultaneous transformation kinetics microstructure model with application to laser metal deposited Ti6Al4V and alloy 718, MS Thesis, The Ohio State University, 2013, http://rave.ohiolink.edu/etdc/view?acc_num = osu 1366023857.

97. Y. Tian, D. McAllister, H. Colijn, M. Mills, D.F. Farson, M.C. Nordin, and S.S. Babu: Metall. Mater. Trans. A, 2014, vol. 45 , pp. $4470-83$.

98. R. Shi S. Khairallah T. Wook Heo M. Rolchigo J.T. McKeown M.J. Matthews: JOM, 2019, vol. 71, pp. 364055.

99. N. Sridharan, A. Chaudhary, P. Nandwana, and S.S. Babu: JOM, 2016, vol. 68, pp. 772-77.

100. V. Thampy, A.Y. Fong, N.P. Calta, J. Wang, A.A. Martin, P.J. Depond, A.M. Kiss, G. Guss, Q. Xing, R.T. Ott, A. van Buren, M.F. Toney, J. Nelson Weker, N.J. Kramer, M.J. Matthews, C.J. Tassone, and K.H. Stone: Sci. Rep., 2020, vol. 10 , p. 1981.

101. C. Kenel D. Grolimund X. Li E. Panepucci V.A. Samson D. Ferreira Sanchez F. Marone C. Leinenbach : Sci. Rep., 2017, vol. 7, p. 16358

102. D. Zhang, D. Qiu, M.A. Gibson, Y. Zheng, H.L. Fraser, D.H. StJohn, and M.A. Easton: Nature, 2019, vol. 576, pp. 91-95.

103. A. Clarke: Nature, 2019, vol. 576, pp. 41-42.

104. B. Karlsson: Mater. Sci. Eng., 1973, vol. 11, pp. 185-93.

105. O.M. Ivasishin and R.V. Teliovich: Mater. Sci. Eng. A, 1999, vol. 263 , pp. $142-54$.

106. H.Z. Zhong, M. Qian, W. Hou, X.Y. Zhang, and J.F. Gu: Mater. Lett., 2018, vol. 216, pp. 50-53. 
107. Y. Wu, S. Zhange, X. Cheng, and H. Wang: J. Alloys Compd., 2019, vol. 799, pp. 325-33.

108. C. Kenel, D. Grolimund, J.L. Fife, V.A. Samson, S. Van Petegem, H. Van Swygenhoven, and C. Leinenbach: Scripta Mater., 2016, vol. 114, pp. 117-120.

109. D.W. Brown, A. Losko, J.S. Carpenter, B. Clausen, J.C. Cooley, V. Livescu, P. Kenesei, J.-S. Park, T.J. Stockman, and M. Strantza: Metall. Mater. Trans. A, 2020, vol. 51A, pp. 1379-94.

110. S.S. Babu: Int. Mater. Rev., 2009, vol. 54, pp. 333-67.

111. M.A. Quintana, J. McLane, S.S. Babu, and S.A. David: Weld. J., 2001, vol. 80, pp. 98s-105s.

112. S.S. Babu, S.M. Kelly, M. Murugananth, and R.P. Martukanitz: Surf. Coat. Technol., 2006, vol. 200 (8), pp. 2663-71.

113. M.P. Haines, N.J. Peter, S.S. Babu, and E.A. Jägle, Addit. Manuf., 2020, vol. 33, \#101178.

114. H. Almostaneer, C. Cadigan, S. Liu, D. Olson, R. Richards, and H.J. Liang: Sci. Technol. Weld. Join., 2011, vol. 16, pp. 619-29.

115. M. Haines, A. Plotkowski, C.L. Frederick, E. Schwalbach, and S.S. Babu: Comput. Mater. Sci., 2018, vol. 155, pp. 340-49.

116. C.L. Frederick, Control of grain structure in selective electron beam melting of nickel based superalloys, $\mathrm{PhD}$ Thesis, University of Tennessee, Knoxville, 2018, https://trace.tennessee.edu/utk_g raddiss $/ 4952$.

117. C. Frederick, M.M. Kirka, M. Haines, A. Staub, E.J. Schwalbach, D. Cullen, and S.S. Babu: Metall. Mater. Trans. A, 2018, vol. 49, pp. 5080-96.

118. J. Sato, T. Omori, K. Oikawa, I. Ohnuma, R. Kainuma, and K. Ishida: Science, 2006, vol. 312, pp. 90-91.

119. A. Suzuki, G.C. DeNolf, and T.M. Pollock: Scr. Mater., 2007, vol. 56, pp. 385-88.

120. T.M. Pollock, J. Dibbern, M. Tsunekane, J. Zhu, and A. Suzuki: JOM, 2010, vol. 62, pp. 58-63.

121. A. Suzuki, H. Inui, and T.M. Pollock: Annu. Rev. Mater. Res., 2015, vol. 45, pp. 345-68.

122. M.S. Titus, Y.M. Eggeler, A. Suzuki, and T.M. Pollock: Acta Mater., 2015, vol. 82, pp. 530-39.

123. A. Mottura, A. Janotti, and T.M. Pollock, Superalloys 2012: Proceedings of the 12th International Symposium on Superalloys, TMS, Warrendale, PA, 2012.

124. M. Tsunekane, A. Suzuki, and T.M. Pollock: J. Intermet., 2011, vol. 19 , pp. 636- 43

125. S. Lu, A. Stoichko, L. Li, and Q. Feng: Metall. Mater. Trans. A., 2018, vol. 49A, pp. 4079-89.

126. M. Knop, P. Mulvey, F. Ismail, A. Radecka, K. M. Rahman, T.C. Lindley, B.A. Shollock, M.C. Hardy, M.P. Moody, T.L. Martin, P.A.J. Bagot, and D. Dye, JOM, 2014, vol. 66, pp. 2495-2501, \#20140.

127. S. Neumeier, L.P. Freund, and M. Göken: Scr. Mater., 2015, vol. 109, pp. 104-07.

128. C.A. Stewart, S.P. Murray, A. Suzuki, T.M. Pollock, and C.G. Levi: Mater. Des., 2020, vol. 189, p. 108445.

129. S.P. Murray, K.M. Pusch, A.T. Polonsky, C.J. Torbet, G.E. Seward, N. Zhou, S.A.J. Forsik, P. Nandwana, M.M. Kirka, R.R. Dehoff, W. Slye, and T.M. Pollock, Nat. Commun., 2020, vol. 11, pp. 1-11.

130. A. Van der Ven, J.C. Thomas, Q. Xu, and J. Bhattacharya, Math. Comput. Sim. 2010, vol. 80, \#1393.

131. A. Van der Ven, J.C. Thomas, B. Puchala, and A.R. Natarajan: Annu. Rev. Mater. Res., 2018, vol. 48, pp. 27-55.

132. R.K. Rhein, P.C. Dodge, M.-H. Chen, M.S. Titus, T.M. Pollock, and A. Van der Ven, Phys. Rev. B, 2015, \#004100.

133. C.A. Stewart, C.G. Levi, and T.M. Pollock, Superalloys 2016: Proceedings of the 13th International Symposium on Superalloys, pp. 991-1000, Wiley, New York, 2016, ISBN 978-1-118-99666-9.

134. C.A. Stewart, T.M. Pollock, A. Suzuki, and C.G. Levi: Oxid. Met., 2018, vol. 90, pp. 485-98.

135. J. Zhu, M.S. Titus, and T.M. Pollock: J. Phase Equilib., 2014, vol. 35, pp. 595-611.

136. L. Feng, D. Lv, R.K. Rhein, J.G. Goiri, M.S. Titus, A. Van der Ven, T.M. Pollock, and Y. Wang: Acta Mater., 2018, vol. 161, pp. 99-109, https://doi.org/10.1016/j.actamat.2018.09.013.

137. J.N. Dupont, J.C. Lippold, and S.D. Kiser: Welding Metallurgy and Weldability of Nickel-Base Alloys, Wiley, New York, 2009.
138. L. Klein, A. Bauer, S. Neumeier, M. Goken, and S. Virtanen: Corros. Sci., 2011, vol. 53, pp. 2027-34.

139. C.A. Stewart, A. Suzuki, R.K. Rhein, T.M. Pollock, and C.G. Levi: Metall. Mater. Trans., 2019, vol. 50A, pp. 5445-58.

140. C.A. Stewart, A. Suzuki, T.M. Pollock, and C.G. Levi: Oxid. Met., 2018, vol. 90, pp. 485-98, https://doi.org/10.1007/s11085018-9849-2.

141. S. Tin and T.M. Pollock: J. Mater. Sci., 2004, vol. 39 (24), pp. 7199-7205.

142. T. Mukherjee, J.S. Zuback, A. De, and T. DebRoy, Sci. Rep., 2016, vol. 6, \#19717.

143. S. Chandrasekar, J.B. Cole, S. Yoder, P. Nandwana, R.R. Dehoff, C.C. Paquit, and S.S. Babu, Addit. Manuf., 2020, vol. 32, $\# 100994$.

144. S.K. Everton, M. Hirsch, P. Stravroulakis, R.K. Leach, and A.T. Clare: Mater. Des., 2016, vol. 95, pp. 431-45.

145. T.G. Spears, and S.A. Gold, Integr. Mater. Manuf. Innov., 2016, vol. 5: \#2.

146. J. Raplee, A. Plotkowski, M. Kirka, R. Dinwiddie, A. Okello, R.R. Dehoff, and S.S. Babu: Sci. Rep., 2017, vol. 7, p. 43554, https://doi.org/10.1038/srep43554.

147. T. Furumoto, M.R. Alkahari, T. Ueda, M.S.A. Aziz, and A. Hosokawa: Phys. Procedia, 2012, vol. 39, pp. 760-66.

148. B. Baucher, A.B. Chaudhary, S.S. Babu, and S. Chakraborty: $J$. Mater. Eng. Perform., 2019, vol. 28, pp. 717-21.

149. T. Grimm, G. Wiora, and G. Witt, Surface. Topogr. Metrol. Prop. 2015, vol. 3, \#014001.

150. S.J. Foster, K. Carver, R.B. Dinwiddie, F. List, III, K.A. Unocic, A. Chaudhary, and S.S. Babu: Metall. Mater. Trans. A, 2018, vol. 49 , pp. $5775-98$

151. J. Mazumder: Procedia CIRP, 2015, vol. 36, pp. 187-92.

152. H. Zhao and T. DebRoy: Metall. Mater. Trans. B, 2001, vol. 32B, pp. 163-72.

153. J. Turner, https://www.exascaleproject.org/wp-content/uploads/ 2018/07/2017-04-19_Turner_ExaAM-v2.pdf.

154. S. Yoder, P. Nandwana, V. Paquit, M. Kirka, A. Scopel, R.R. Dehoff, and S.S. Babu: Addit. Manuf., 2019, vol. 28, pp. $98-106$

155. Y.S. Lee, M.M. Kirka, R.B. Dinwiddie, N. Raghavan, J. Turner, R.R. Dehoff, and S.S. Babu: Addit. Manuf., 2018, vol. 22, pp. 516-27.

156. M. Megahed, H.-W. Mindt, J. Willems, P. Dionne, L. Jacquemetton, J. Craig, P. Ranade, and A. Peralta: Integr. Mater. Manuf. Innov., 2019, vol. 8, pp. 194-216.

157. C. Zhao, K. Fezzaa, R.W. Cunningham, H. Wen, F. De Carlo, L. Chen, A.D. Rollett, and T. Sun: Sci. Rep., 2017, vol. 7, p. 3602 .

158. S.M.H. Hojjatzadeh, N.D. Parab, W. Yan, Q. Guo, L. Xiong, C. Zhao, M. Qu, L.I. Escano, X. Xiao, K. Fezzaa, W. Everhart, T. Sun, and L. Chen: Nat. Commun., 2019, vol. 10, p. 3088.

159. R. Cunningham, C. Zhao, N. Parab, C. Kantzos, J. Pauza, K. Fezzaa, T. Sun, and A.D. Rollett: Science, 2019, vol. 363, pp. $849-52$

160. N. Kouraytem, X. Li, R. Cunningham, C. Zhao, N. Parab, T. Sun, A.D. Rollett, A.D. Spear, W. Tan, Phys. Rev. Appl., 2019, vol. 11, \#064054.

161. Q. Guo, C. Zhao, M. Qu, L. Xiong, L.I. Escano, S.M.H. Hojjatzadeh, N.D. Parab, K. Fezzaa, W. Everhart, T. Sun, and L. Chen: Addit. Manuf., 2019, vol. 28, pp. 600-09.

162. C. Lun Alex Leung, A. Marussi, R.C. Atwood, M. Towrie, P.J. Withers, P.D. Lee, Nat. Commun., 2018, vol. 9, \#1355.

163. N.D. Parab, C. Zhao, R. Cunningham, L.I. Escano, K. Fezzaa, W. Everhart, A.D. Rollett, L. Chen, and T. Sun: J. Synchrotron Radiat., 2018, vol. 25, pp. 1467-77.

164. A. Bobel, L.G. Hector Jr., I. Chelladurai, A.K. Sachdev, T. Brown, W.A. Poling, R. Kubic, B. Gould, C. Zhao, N. Parab, A. Greco, T. Sun, Materialia, 2019, vol. 6, \#100306.

165. S.J. Wolff, H. Wu, N. Parab, C. Zhao, K.F. Ehmann, T. Sun, J. Cao, Sci. Rep., 2019, vol. 9, \#962.

166. L.I. Escano, N.D. Parab, L. Xiong, Q. Guo, C. Zhao, T. Sun, and L. Chen: Synchrotron Radiat. News, 2019, vol. 32, pp. 9-13.

167. A.M. Kiss, A.Y. Fong, N.P. Calta, V. Thampy, A.A. Martin, P.J. Depond, J. Wang, M.J. Matthews, R.T. Ott, C.J. Tassone, K.H. Stone, M.J. Kramer, A. van Buuren, M.F. Toney, J. Nelson Weker, Adv. Eng. Mater., 2019, vol. 21, \#1900455. 
168. A.A. Martin, N.P. Calta, A.A. Khairallah, J. Wang, P.J Depond, A.Y. Fong, V. Thampy, G.M. Guss, A.M. Kiss, K.H. Stone, C.J. Tassone, J. Nelson Weker, M.F. Toney, T. van Buuren, M.J. Matthews, Nat. Commun., 2019, vol. 10, \#1987.

169. A.A. Martin, N.P. Calta, J.A. Hammons, S.A. Khairallah, M.H. Nielsen, R.M. Shuttlesworth, N. Sinclair, M.J. Matthews, J.R. Jeffries, T.M. Willey, J.R.I. Lee, Mater. Today Adv., 2019, vol. 1, \#100002.

170. N.P. Calta, J. Wang, A.M. Kiss, A.A. Martin, P.J. Depond, G.M. Guss, V. Thampy, A.Y. Fong, J. Nelson Weker, K.H. Stone, C.J. Tassone, M.J. Kramer, M.F. Toney, A. van Buuren, M.J. Matthews, Rev. Sci. Instrum., 2018, vol. 89, \#055101.

171. C. Kenel, D. Grolimund, J.L. Fife, V.A. Samson, S. Van Petegem, H. Van Swygenhoven, and C. Leinenback: Scr. Mater., 2016, vol. 114, pp. 117-20.

172. T. LaGrange, B.W. Reed, M.K. Sanatla, J.T. McKeown, A. Kulovits, J.M. Wiezorek, L. Nikolova, F. Rosei, B.J. Siwick, and G.H. Campbell: Micron, 2012, vol. 43, pp. 1108-20.

173. T. LaGrange, B.W. Reed, D.J. Masiel, MRS Bull., 2015, vol. 40. \#2228.

174. J.T. McKeown, A.K. Kulovitd, C. Liu, K. Zweiacker, B.W. Reed, T. LaGrange, J.M.K. Wiezorek, and G.H. Campbell: Acta Mater., 2014, vol. 65, pp. 56-68.

175. J.T. McKeown, K. Zweiacker, C. Liu, D.R. Coughlin, A.J. Clarke, J.K. Baldwin, J.W. Gibbs, J.D. Roehling, S.D. Imhoff, P.J. Gibbs, D. Tourret, J.M.K. Wiezorek, and G.H. Campbell: JOM, 2016, vol. 68, pp. 985-99.

176. A. Perron, J.D. Roehling, P.E.A. Turchi, J.-L. Fattebert, J.T. McKeown, Modell. Simul. Mater. Sci. Eng., 2018, vol. 26, $\# 014002$.

177. K. Zweiacker, J. McKeown, C. Liu, T. LaGrange, B. Reed, G. Campbell, and J. Wiezorek, J. Appl. Phys., 2016, vol. 120, \#055106.

178. T. Pinomaa, J.T. McKeown, J.M.K. Wiezorek, N. Provatas, A. Laukkanen, and T. Suhonen, J. Cryst. Growth, 2020, vol. 532, \#125418.

179. A.J. Clarke, D. Tourret, Y. Song, S.D. Imhoff, P.J. Gibbs, J.W. Gibbs, K. Fezzaa, and A. Karma: Acta Mater., 2017, vol. 129 , pp. 203-16.

180. D. Tourret, A.J. Clarke, S.D. Imhoff, P.J. Gibbs, J.W. Gibbs, and A. Karma: JOM, 2015, vol. 67, pp. 1776-85.

181. D. Tourret, A. Karma, A.J. Clarke, P.J. Gibbs, and S.D. Imhoff, Mater. Sci. Eng., 2015, vol. 84, \#012082.

182. D. Tourret, J.C.E. Mertens, E. Lieberman, S.D. Imhoff, J.W. Gibbs, K. Henderson, K. Fezzaa, A.L. Diery, R. Lebensohn, B.M. Patterson, and A.J. Clarke: Metall. Mater. Trans. A, 2017, vol. 48, pp. 5529-46.
183. M.F. Francois, A. Sun, W.E. King, N.J. Henson, D. Tourret, C.A. Bronkhorst, N.N. Carlson, C.K. Newman, T.S. Haut, J. Bakosi, J.W. Gibbs, V. Livescu, S.A. Vander Wiel, A.J. Clarke, M.W. Schraad, T. Blacker, H. Lim, T. Rodgers, S. Owen, F. Abdeljawad, J. Madison, A.T. Anderson, J.-L. Fttebert, R.M. Ferencz, N.E. Hodge, S.A. Khairallah, and O. Walton: Curr. Opin. Solid State Mater. Sci., 2017, vol. 21, pp. 198-206.

184. A.I. Saville, S.C. Vogel, A. Creuziger, J.T. Benzing, A. Pilchak, J. Klemm-Toole, S. Babu, and A.J. Clarke, Texture evolution as a function of scan strategy and build height in electron beam melted Ti-6Al-4V, unpublished research, Colorado School of Mines, 2020.

185. P. Nandwana, Y. Lee, C. Ranger, A.D. Rollett, R.R. Dehoff, and S.S. Babu: Metall. Mater. Trans. A, 2019, vol. 50A, pp. 3430-39.

186. G.T. Gray, V. Livescu, P.A. Rigg, C.P. Trujillo, C.M. Cady, S.R. Chen, J.S. Carpenter, T.J. Lienert, and S.J. Fensin: Acta Mater., 2017, vol. 138, pp. 140-49.

187. L. Kolbus, A. Payzant, P. Cornwell, T. Watkins, S.S. Babu, R. Dehoff, and C. Duty: Metall. Mater. Trans. A, 2015, vol. 46 (3), pp. 1419-32

188. E. Cakmak, T.R. Watkins, J.R. Bunn, R.C. Cooper, P.A. Cromwell, Y. Wang, L. Sochalski-Kolbus, E.A. Payzant, R.R. Dehoff, and S.S. Babu: Metall. Mater. Trans. A., 2016, vol. 47, pp. 971-80.

189. A. du Plessis, I. Yadroitsev, I. Yadroitsava, and S.G. Le Roux: 3D Print. Addit. Manuf., 2018, vol. 5, pp. 227-47.

190. C.J. Todaro, M.A. Easton, D. Qiu, D. Zhang, M.J. Bermingham, E.W. Lui, M. Brandt, D.H. St. John, and M. Qian, Nat. Commun., 2020, vol. 11, \#142.

191. B.R. Goodlet, L. Mills, B. Bales, M.-A. Charpagne, S.P. Murray, W.C. Lenthe, L. Petzold, and T.M. Pollock: Metall. Mater. Trans., 2018, vol. 49A, pp. 2324-39.

192. M.L. Latypov, M.-A. Charpagne, M. Souther, B.R. Goodlet, M.P. Echlin, and T.M. Pollock: Mater. Charact., 2019, vol. 145, pp. $671-85$

193. W.E. Frazier, D. Polakovics, and W. Koegel: JOM, 2001, vol. 53, pp. 16-18.

194. D. Mies, W. Marsden, and S. Warde, Integr. Mater. Manuf. Innov., 2016, vol. 5, 6, pp. 1-29.

195. T. Debroy, S.S. Babu, W. Zhang, and J. Turner: Scr. Mater., 2017, vol. 135, pp. 119-24.

196. Z. $\mathrm{Hu}$ and S. Mahadevan: Scr. Mater., 2017, vol. 135, pp. $135-40$.

Publisher's Note Springer Nature remains neutral with regard to jurisdictional claims in published maps and institutional affiliations. 